\title{
Loss of C3aR induces immune infiltration and inflammatory microbiota in a new spontaneous model of colon cancer
}

Carsten Krieg ${ }^{1}$, Sara Carloni ${ }^{2 \S}$, Lukas M. Weber ${ }^{3,4 \#}$, Bruno Fosso ${ }^{5}$, Gary Hardiman ${ }^{6}$, Erika Mileti $^{2}$, Sahar El Aidy ${ }^{7}$, Marinella Marzano ${ }^{5}$, Graziano Pesole $^{8}$, Francesco Asnicar ${ }^{9}$, Nicola Segata $^{9}$, Mark D. Robinson ${ }^{3,4}$, Silvia Guglietta ${ }^{1,2^{*}}$

${ }^{1}$ Department of Microbiology and Immunology, Hollings Cancer Center, Medical University of South Carolina, 29425 Charleston (SC), USA.

${ }^{2}$ Department of Experimental Oncology, IEO European Institute of Oncology IRCCS, Milan, Italy

${ }^{3}$ Institute of Molecular Life Sciences, University of Zurich, Winterthurerstr. 190, CH-8057

Zurich, Switzerland

${ }^{4}$ SIB Swiss Institute of Bioinformatics, University of Zurich, Winterthurerstr. 190, CH-8057 Zurich, Switzerland

${ }^{5}$ Institute of Biomembranes, Bioenergetics and Molecular Biotechnologies, Consiglio Nazionale delle Ricerche, Bari, Italy

${ }^{6}$ School of Biological Sciences \& Institute for Global Food Security, Queens University Belfast, BT9 5AG, Belfast, UK

${ }^{7}$ Host-microbe metabolic interactions, Microbiology, Groningen Biomolecular Sciences and Biotechnology Institute (GBB), University of Groningen, Groningen, The Netherlands

${ }^{8}$ Department of Biosciences, Biotechnology and Biopharmaceutics, University of Bari, 70124 Bari, Italy

${ }^{9}$ Department CIBIO, University of Trento, Trento, Italy 
\# Present address: Department of Biostatistics, Johns Hopkins Bloomberg School of Public Health, Baltimore, MD 21205, USA

${ }^{\S}$ Present address: Mucosal Immunology and Microbiota Unit, Humanitas Clinical and Research Center-IRCCS, Via Manzoni 56, 20089 Rozzano, Milan, Italy.

*Correspondence: e-mail: gugliett@musc.edu

\section{ABSTRACT}

Several lines of evidence suggest that inflammation plays a pivotal role in the development and progression of colorectal cancer (CRC) and can be unleashed by the loss of innate immunosurveillance. The complement system is a well characterized first line of defense against pathogens and a central component of the immune response. Emerging evidence suggests that complement anaphylatoxin C3a produced upon complement activation and acting via its receptor $(\mathrm{C} 3 \mathrm{aR})$ may play a role in intestinal homeostasis. However, to date, it is unknown whether and how the $\mathrm{C} 3 \mathrm{a} / \mathrm{C} 3 \mathrm{aR}$ axis can affect $\mathrm{CRC}$. By mining publicly available datasets, we found that $\mathrm{CpG}$ island methylation of c3arl occurs in CRC patients and is associated with significant downregulation of $\mathrm{C} 3 \mathrm{aR}$. By reverse-translating this finding we were able to shift in $\mathrm{APC}^{\mathrm{Min} /+}$ mice the tumorigenesis from the small intestine to the colon therefore generating a novel mouse model, which more closely mirrors the CRC in humans. Transcriptomic analysis on colorectal polyps from our newly developed genetic mouse model revealed a significant increase in innate and adaptive immune signatures in absence of C3aR. Furthermore, loss of C3aR significantly impacted the fecal and tumor-associated microbiota and supported the blooming of proinflammatory bacterial species as confirmed by experiments of fecal microbiota transplantation. 
Future studies will elucidate whether loss of C3aR can be exploited as a biomarker for subgroups of $\mathrm{CRC}$ and whether the $\mathrm{C} 3 \mathrm{a} / \mathrm{C} 3 \mathrm{aR}$ axis may be exploited for the generation of more effective therapeutic interventions.

\section{INTRODUCTION}

Colorectal cancer (CRC) is the third most diagnosed cancer worldwide and the first cause of non-smoking-related cancer deaths and it is expected to increase by $60 \%$ with 2.2 million new cases and 1.1 million deaths annually by the year 2030 (Arnold et al., 2017; Siegel et al., 2018). This trend is even more alarming considering that recent data show increased incidence of CRC in young adults, who often experience more aggressive disease and lower survival than the older population (Siegel et al., 2020). While early screening, surgery and adjuvant therapies have significantly improved CRC outcome, still about $30 \%$ of patients with CRC undergo recurrence and develops metastatic disease, therefore suggesting that the discovery of new treatments with improved efficacy is highly desirable. A major obstacle to the identification of more effective therapies is the lack of suitable preclinical mouse models that closely mirror the multi-step process of CRC development in humans. Attempts to model human CRC using transgenic mice carrying known genetic mutations that occur in human CRC resulted in the development of several models, which share similar limitations: lack of invasive phenotype, development of multiple adenomas localized in the small intestine rather than in the colon, low penetrance and low reproducibility (Burtin et al., 2020; Fodde et al., 2001). This is not surprising if we consider that genetic mutations represent only a piece of the very complex puzzle of human $\mathrm{CRC}$, where epigenetic alterations, environmental and host-associated factors are emerging as major determinants in the origin and the heterogeneity of the tumors (Pancione et al., 2012). Therefore, identifying additional events that primarily cause tumor initiation may represent a successful 
strategy to more closely model the human disease in mice. The gastrointestinal tract is among the largest mucosal surfaces in the body and mounting prompt and efficacious innate immune responses is indispensable to maintaining homeostasis and preventing harmful inflammation. In support of this observation, deficiencies in innate sensing mechanisms have been associated with increased intestinal inflammation and CRC in human and mouse models (Coleman et al., 2018; de Souza et al., 2018; Garrett et al., 2007; Rakoff-Nahoum and Medzhitov, 2007; Salcedo et al., 2010). The complement system represents the first line of defense against pathogens and is a central player in immunity due to its ability to establish extensive networks with other innate immune pathways (Arbore et al., 2016; Hajishengallis and Lambris, 2010; Ostvik et al., 2014; Zhang et al., 2007).

We previously reported that activation of the alternative complement pathway occurs during spontaneous small intestinal tumorigenesis and that the $\mathrm{C} 3 \mathrm{a}-\mathrm{C} 3 \mathrm{aR}$ axis is involved in tumorassociated thrombosis via promotion of NET formation (Guglietta et al., 2016). Furthermore, in a model of intestinal ischemia/reperfusion injury, the $\mathrm{C} 3 \mathrm{a}-\mathrm{C} 3 \mathrm{aR}$ axis proved essential for tissue regeneration and protection from oxidative damage (Wu et al., 2013). In light of these findings, which suggest a critical function for the $\mathrm{C} 3 \mathrm{a} / \mathrm{C} 3 \mathrm{aR}$ axis in intestinal homeostasis, we set out to investigate its role in the development of human CRC. By mining publicly available gene expression datasets, we found that c3arl in CRC patients is among the top $1 \%$ down-regulated genes. Notably, we found that c3arl down-regulation in human is primarily associated with $\mathrm{CpG}$ island methylation rather than somatic mutations. We then reverse translated our finding from CRC patients into $\mathrm{APC}^{\mathrm{Min} /+}$ mice, which carry a mutation in the apc gene and mainly develop polyps in the small intestine (Fodde et al., 2001; Guglietta et al., 2016). Notably, by knocking down $\mathrm{C} 3 \mathrm{aR}$, therefore generating $\mathrm{APC}^{\mathrm{Min} /+} / \mathrm{C} 3 \mathrm{aR}-/-$ mice, we observed an unprecedent shift of 
tumor growth from the small intestine to the colon and a significant induction of innate and adaptive immune responses. These events were dependent on gut microbiota. Indeed, the disruption of the $\mathrm{C} 3 \mathrm{a} / \mathrm{C} 3 \mathrm{aR}$ axis affected both the fecal and tumor-associated microbiota and fecal microbiota transplantation effectively reproduced in $\mathrm{APC}^{\mathrm{Min} /+}$ mice the immune infiltrate and tumor growth observed in $\mathrm{APC}^{\mathrm{Min} /+} / \mathrm{C} 3 \mathrm{aR}-/-$ mice. Altogether, based on our findings in human $\mathrm{CRC}$, by disrupting the $\mathrm{C} 3 \mathrm{a} / \mathrm{C} 3 \mathrm{aR}$ axis, we generated a new spontaneous $\mathrm{CRC}$ models whereby immune responses, microbiota and genetic alterations contribute to the development of tumors in the colon, more closely resembling the human disease. Future studies will determine whether the absence of $\mathrm{C} 3 \mathrm{aR}$ could be exploited for therapeutic intervention and whether C3aR could serve as biomarker for diagnostic and therapeutic purposes in CRC.

\section{RESULTS}

\section{c3ar1 down-regulation occurs in CRC patients}

Analysis of the gene expression libraries provided through the Skrzypczack Colorectal cohort, Sabates-Bellver Colon cohort, Ki Colon cohort and TCGA cohort (https://www.oncomine.org), showed that in sub-groups of both rectal and colon cancer patients c3arl is downregulated compared to controls (Fig. 1a). Because mutations of single genes in the complement pathway are very rare, we reasoned that down-regulation of the c3arl gene could be more efficiently mediated by epigenetic modifications (Olcina et al., 2018). Methylation occurs at high frequency in CRC and it has been shown to also induce silencing of tumor suppressor genes (Tse et al., 2017). In order to assess this possibility, we mined the MethHC database of DNA methylation and gene expression in human cancer (http://methhc.mbc.nctu.edu.tw) and found that $c 3$ arl gene is more highly methylated in CRC tissues as compared to the paired normal mucosa (Huang et 
al., 2015). Remarkably, significant hypermethylation was seen in the $\mathrm{N}$ and $\mathrm{S}$ shores (regions up to $2 \mathrm{~kb}$ away from $\mathrm{CpG}$ islands) and in the shelves (Fig. 1b-d). As shown by Irizarry and collaborators, DNA methylation in the $\mathrm{N}$ and $\mathrm{S}$ shores of $\mathrm{CpG}$ islands inversely correlates with gene expression levels (Irizarry et al., 2009). These results suggest that the downregulation of $\mathrm{C} 3 \mathrm{aR}$ in $\mathrm{CRC}$ could be due to $\mathrm{CpG}$ island methylation events, that have been shown to be prominent for the development of CRC (Jung et al., 2020). Taken together these findings support the hypothesis that $\mathrm{C} 3 \mathrm{aR}$ plays a previously unrecognized role in intestinal homeostasis and loss or reduction of its expression due to DNA methylation or mutations occurs in CRC patients.

\section{C3a/C3aR axis plays a previously unappreciated role in CRC development.}

While we found that $\mathrm{C} 3 \mathrm{aR}$ is down-regulated in $\mathrm{CRC}$ patients, the functional significance of this phenomenon for the tumorigenic process is unknown. To test the role of the $\mathrm{C} 3 \mathrm{a} / \mathrm{C} 3 \mathrm{aR}$ axis in CRC development, we reverse translated our finding from the database into mouse models. First, age-and sex-matched C3aR-/- and WT mice were administered the carcinogen azoxymethane (AOM) followed by three cycles of the inflammatory agent dextran sodium sulphate (DSS) and their body weight was monitored every other day until day 70, when tumor number and size were quantified. Relative to WT, C3aR-/- mice showed increased weight loss and reduced survival throughout the experiment (Fig. 2a-b) suggesting that C3aR protects from excessive intestinal inflammation. This result is in agreement with previously published literature showing that lack of complement activation in C3-/- mice exacerbates chronic intestinal inflammation (Elvington et al., 2015). Notably, as shown in Fig. 2c-e, at the end of the experiment, C3aR-/mice developed significantly higher tumor number and higher tumor load in the colon as compared to the WT mice, with predominance of larger tumors ( $>2 \mathrm{~mm})$. As innate and adaptive 
immune responses are both involved in colon inflammation and tumorigenesis, we set up three interlinked flow cytometry

panels to characterize the immune infiltrate in the tumors and in the mesenteric lymph nodes (mLN). As shown in Fig. 2f-h, we found higher numbers of CD4+ IL17A+ (Th17) and IFN- $\gamma+\mathrm{T}$ cells (Th1) cells and increased CD11c+ macrophages in the mLN of C3aR-/- mice with no significant differences in the amount of FoxP3+CD25+ Tregs. In contrast, while no differences relative to WT were observed in dendritic cell and macrophage subsets in the tumors of C3aR-/mice (Fig. 2i), we found significantly higher numbers of Tregs, and IFN- $\gamma+/$ IL17A+CD4+T cells (Th1/Th17) compared to WT mice (Fig. 2j-k). Although more than $20 \%$ of individuals with IBD develop CRC, intestinal inflammation accounts for only about $2 \%$ of total CRC (Munkholm, 2003). Therefore, we next investigated the impact of C3aR loss in the APC ${ }^{\mathrm{Min} /+}$ spontaneous model, which like $80 \%$ of human CRC (Polakis, 2012), carries a mutation of the apc gene. We generated $\mathrm{APC}^{\mathrm{Min} /+}$ mice lacking the $c 3$ arl gene (APC $\left.{ }^{\mathrm{Min} /+} / \mathrm{C} 3 \mathrm{aR}-/-\right)$ and compared tumor development in the colon from 5 to 28 weeks of age in the $\mathrm{APC}^{\mathrm{Min} /+}$ and $\mathrm{APC}{ }^{\mathrm{Min} /+} / \mathrm{C} 3 \mathrm{aR}-/-$ mice. We and others have shown that in $\mathrm{APC}^{\mathrm{Min} /+}$ mice $\mathrm{CRC}$ development is sporadic, with the highest tumor burden in the distal small intestine (Fodde et al., 2001; Guglietta et al., 2016; Haigis et al., 2004). In line with the human data and the results in the model of inflammationdriven $\mathrm{CRC}$, we found that in the absence of $\mathrm{C} 3 \mathrm{aR}$, starting at 10 weeks of age, $\mathrm{APC}{ }^{\mathrm{Min} /+}$ mice showed a shift of tumorigenesis from the small intestine to the colon with the highest localization in distal colon and rectum (Fig. 3a and b). Similar to the approach used in the AOM/DSS model, we performed flow cytometry to quantify the immune infiltrate associated with tumor development. Due to the very low number of colon tumors in $\mathrm{APC}^{\mathrm{Min} /+}$ mice, we analyzed the mLN and the colon lamina propria (cLP) by flow cytometry. Similar to the results obtained in 
the AOM/DSS model, loss of C3aR resulted in significantly higher numbers of Th17, Th1, Th1/Th17 and CD8+ T cells in the cLP of $\mathrm{APC}^{\mathrm{Min} /+} / \mathrm{C} 3 \mathrm{aR}-/-$ mice compared to the $\mathrm{APC}$ Min/+ counterpart (Fig. 3c-h). In the mLN no differences were found in the functional subsets despite higher numbers of $\mathrm{CD} 4+$ and $\mathrm{CD} 8+\mathrm{T}$ cells in the $\mathrm{APC}^{\mathrm{Min} /+} / \mathrm{C} 3 \mathrm{aR}-/-$ mice compared to $\mathrm{APC} \mathrm{Min} /+^{-}$ mice (Fig. S1a-f). The role and prognostic significance of infiltrating immune cells in the lamina propria and tumors of C3aR-/- mice is currently unknown. However, the coexistence of T regs, Th17 and IFN- $\gamma$-producing CD8+T cells in the tumors and cLP of both mouse models is in line with published literature showing that Tregs can promote Th17 cell infiltration during CRC and that Th17 in human CRC recruit CD8+T cells (Amicarella et al., 2017; Watanabe et al., 2016). Altogether by disrupting the $\mathrm{C} 3 \mathrm{a} / \mathrm{C} 3 \mathrm{aR}$ axis, we generated a novel mouse model, which spontaneously develops colon tumors and therefore more closely mirrors the disease in humans. Our findings confirm the data in $\mathrm{CRC}$ patients and suggest that the $\mathrm{C} 3 \mathrm{a} / \mathrm{C} 3 \mathrm{aR}$ axis play a previously unappreciated role in colon cancer and inflammation.

\section{Disruption of the $\mathrm{C3a} / \mathrm{C3aR}$ axis results in transcriptional up-regulation of innate and adaptive immune pathways in the healthy distal colon of $\mathrm{APC}^{\mathrm{Min} /+} / \mathrm{C3aR}-/-$ mice.}

To understand how lack of $\mathrm{C} 3 \mathrm{aR}$ shapes the tumor microenvironment and the adjacent healthy mucosa in our newly developed spontaneous mouse model of colon tumorigenesis, we performed RNA-Seq analysis in 8 and 12-week-old $\mathrm{APC}^{\mathrm{Min} /+}$ and $\mathrm{APC}^{\mathrm{Min} /+} / \mathrm{C} 3 \mathrm{aR}-/-$ and used WT and C3aR-/- littermates as respective controls. Noting that absence of C3aR induced prevalent development of tumors in the distal colon and rectum, we suspected that the absence of C3aR might have a more profound effect on the microenvironment of the distal colon. Therefore, for RNA-Seq studies, proximal and distal colon were kept separated. When performing the comparison between the healthy colons among all the strains and the subsequent gene clustering 
to generate the heatmap, we observed that $\mathrm{APC}^{\mathrm{Min} /+}$ mice had a more similar transcriptomic profile to WT mice than to $\mathrm{APC}{ }^{\mathrm{Min} /+} / \mathrm{C} 3 \mathrm{aR}-/-$ mice, and similarly, healthy colons of C3aR-/mice exhibited a transcriptomic profile more similar to the colons of $\mathrm{APC}{ }^{\mathrm{Min} /+} / \mathrm{C} 3 \mathrm{aR}-/-$ than to the colons of WT mice (Fig. 4a and Suppl. Fig. 2a-f). These results show that the absence of $\mathrm{C} 3 \mathrm{aR}$, rather than the presence of tumors, shapes the transcriptomic profile of tumor-adjacent healthy mucosa. Using the edgeR-GLM framework (see Methods), we then tested the differential gene expression profile in distal colon and tumors of $\mathrm{APC}^{\mathrm{Min} /+}$ compared to $\mathrm{APC}{ }^{\mathrm{Min} /+} / \mathrm{C} 3 \mathrm{aR}-/-$ mice. As shown in Fig. S2f, by using a 2-fold threshold, C3aR loss resulted in a significant change in the expression level of 318 genes in the healthy distal colon, out of which 235 were up-regulated and 83 down-regulated. Notably, iPathway analysis revealed that the top 25 Gene Ontology (GO) biological processes associated with differentially expressed genes were related to innate and adaptive immune responses (Fig. 4b). Accordingly, in the distal colon of $\mathrm{APC}^{\mathrm{Min} /+} \mathrm{C} 3 \mathrm{aR}-/-$ mice, we observed a significant up-regulation of genes involved in the response to bacteria (nos2, noxl, ltf and s100a9); adaptive immune responses-related genes (ill $8 b p$, ifn- $\gamma$, granzyme $a$ and $b, k \operatorname{lrc} 3$ ), ifn- $\gamma$-mediated signaling genes (stat $1, n l r c 5, g b p 2)$. In contrast, in the distal colon of $\mathrm{APC}^{\mathrm{Min} /+} / \mathrm{C} 3 \mathrm{aR}-/-$ mice we found a significant down regulation of defensin genes involved in the response to bacteria such as regland reg3a, (Cash et al., 2006) and several genes encoding for solute carrier transporters such as slc30a10, slc35e3, slc20al and slc10a2 (Fig. 4c).

Colon tumors from $\mathrm{APC}^{\mathrm{Min} /+} / \mathrm{C} 3 \mathrm{aR}-/-$ show an enrichment in inflammatory immune pathways

We next compared the transcriptomic profile of colon tumors developed by APC ${ }^{\mathrm{Min} /+}$ and $\mathrm{APC}^{\mathrm{Min} /+} / \mathrm{C} 3 \mathrm{aR}-/-$ mice. Using a 2-fold threshold, we found 72 downregulated genes and 369 
upregulated genes in colon polyps from $\mathrm{APC}^{\mathrm{Min} /+} / \mathrm{C} 3 \mathrm{aR}-/-$ mice, clearly indicating that loss of C3aR affects the transcriptomic profile of the polyps (Fig. 5a).

In line with the results from the healthy mucosa of the distal colon, iPathway analysis revealed that the top 25 Gene Ontology (GO) biological processes associated with differentially expressed genes in the polyps were related to innate and adaptive immune responses (Figure $5 b$ ). Accordingly, in the tumors of $\mathrm{APC}^{\mathrm{Min} /+} / \mathrm{C} 3 \mathrm{aR}-/-$ mice, we found significant up-regulation of genes associated with defense response, such as $c d 8, c c r 6, i l 21, c d 19, i l 22 r a 2$; IFN- $\gamma$-mediated signaling pathway-related genes, such as ifi and guanylate-binding protein (GBP) family genes tap-1, ciita, $\beta 2$-microglobulin and stat1; genes associated with development and maturation of innate immune cells and response to type I interferon such as irf4 and irf8 and $c d 83$; negative regulator of the immune response, such as btla, $c d 274$ (pd-ll), $c d 40 l g$ and idol; genes associated with leucocyte migration such as, $\operatorname{cxcl9}$, cxcl10, $\operatorname{cxcl11}$ and $\operatorname{cxcr5}$; NK cell activation genes such as $i l-12 b$ and $n c r l$. Among the significantly down-regulated genes, we found genes for transporters including slc47 and slc44a5 and Wnt signaling pathway inhibitors such as $d k k 2$ and $d k k 3$ (Fig. 5c). These latter have recently been shown to be up-regulated following apc loss in CRC patients and to mediate the failure of anti-PD1 treatment in MSS-high CRC by dampening NK and CD8-mediated anti-tumor immune responses (Xiao et al., 2018). Altogether, the results from our transcriptomic analysis suggest that loss of $\mathrm{C} 3 \mathrm{aR}$ promotes a vigorous inflammatory signature in the colon and in the tumors of $\mathrm{APC}^{\mathrm{Min} /+}$ mice.

\section{$\mathrm{APC}^{\mathrm{Min} /+} / \mathrm{C3aR}-/-$ microbiota transplantation transfers tumor growth to $\mathrm{APC}^{\mathrm{Min} /+}$ mice}

Because evidence suggests that CRC tumor development is strictly influenced by the microbial flora (Ahn et al., 2013; Arthur et al., 2014; Dejea et al., 2018; Tilg et al., 2018; Wu et al., 2009), we sought to understand whether the transfer of $\mathrm{APC}^{\mathrm{Min} /+} / \mathrm{C} 3 \mathrm{aR}-/-$ microbiota could increase 
tumor development in the colon of $\mathrm{APC}^{\mathrm{Min} /+}$ mice. Tumor-free, five-week-old $\mathrm{APC}{ }^{\mathrm{Min} /+}$ mice were treated with broad-spectrum antibiotics, then administered via gavage with fecal microbiota from 12-week-old $\mathrm{APC}^{\mathrm{Min} /+} / \mathrm{C} 3 \mathrm{aR}-/-$ mice or $\mathrm{APC}^{\mathrm{Min} /+}$ mice and sacrificed at the age of 12 weeks (Fig. 6a). As shown in Fig. 6b, while $\mathrm{APC}^{\mathrm{Min} /+}$ mice receiving the $\mathrm{APC}^{\mathrm{Min} /+}$ microbiota developed very few tumors in the colon, the transfer of $\mathrm{APC}^{\mathrm{Min} /+} / \mathrm{C} 3 \mathrm{aR}-/-$ microbiota resulted in increased tumor burden in the colon, with no changes in the total number of small intestinal tumors (Suppl. Fig. 3a-b). To test whether the microbiota could impact immune cell recruitment in the colon of microbiota-transplanted mice, we used flow cytometry to characterize the immune cell infiltrate in the $\mathrm{APC}^{\mathrm{Min} /+}$ mice receiving $\mathrm{APC}^{\mathrm{Min} /+}$ or $\mathrm{APC}^{\mathrm{Min} /+} / \mathrm{C} 3 \mathrm{aR}-/-$ microbiota. As shown in Fig. 6c-h and Suppl. Fig. 3c-h, APC ${ }^{\mathrm{Min} /+}$ mice receiving APC ${ }^{\mathrm{Min} /+} / \mathrm{C} 3 \mathrm{aR}-/-$ feces showed higher tumor numbers in the colon and increased Th1, Th17 and Th1/Th17 cell infiltration in the lamina propria. Altogether, these data clearly demonstrated that, besides affecting colon tumor development, the microbiota transplantation from $\mathrm{APC}^{\mathrm{Min} /+} / \mathrm{C} 3 \mathrm{aR}-/-$, but not $\mathrm{APC}^{\mathrm{Min} /+}$ mice, recapitulated the immune signature that we described at protein and RNA level in colon and tumors of mice lacking the C3aR signaling.

\section{Loss of C3aR affects the composition of the fecal and tumor-associated microbiota in $\mathrm{APC}^{\mathrm{Min} / \mathrm{H}}$ mice}

Although several lines of evidences have shown that the complement system plays a fundamental protective role against pathogens, there is a lack of studies regarding the possible role of complement in controlling a pro-tumorigenic microbiota. Recently, C5aR has been shown to play an important role in the composition of skin microbiota and the associated inflammatory immune responses (Chehoud et al., 2013). Further, C3a has been demonstrated to be a potent anti-microbial agent (Nordahl et al., 2004). To better understand whether the results obtained 
with the microbiota transplantation were the consequence of a tumor-associated microbiota or a change in microbiota composition driven by $\mathrm{C} 3 \mathrm{aR}$ deficiency, we characterized the microbiota before and after tumor development. For this purpose, we collected the fecal pellet from tumor free eight-week-old and tumor-bearing 12-week-old $\mathrm{APC}^{\mathrm{Min} /+}$ and $\mathrm{APC}^{\mathrm{Min} /+} / \mathrm{C} 3 \mathrm{aR}-/-$ mice. Bacterial DNA was extracted from fecal pellets as detailed in the experimental procedures. The V5-V6 hypervariable regions of bacterial 16S rRNA gene were amplified and the obtained libraries were sequenced on the MiSeq Illumina platform. Compared to controls, we observed higher alpha diversity in eight-week-old $\mathrm{APC}^{\mathrm{Min} /+} / \mathrm{C} 3 \mathrm{aR}-/-$ and $\mathrm{C} 3 \mathrm{aR}-/-$ mice measured by observed ASV, Faith and Shannon index (Fig. 7a). The alpha diversity normalized then in 12week-old mice, although there was still a clear separation among the two mouse strains in terms of beta diversity (Fig. 7b). These results support the concept that the fecal microbiota that precedes tumor growth is highly diversified within the same group. In contrast, upon tumor development, the selection of defined bacterial species results in reduced intra-group and enhanced inter-group diversification. When examining the differences in the most abundant phyla, we observed that, already at 8 weeks when the mice in our colony are devoid of tumors in both small intestine and colon, in $\mathrm{APC}^{\mathrm{Min} /+} / \mathrm{C} 3 \mathrm{aR}-/-$ mice there was increased Bacteroidetes and Proteobacteria and evident reduction of Firmicutes as compared to $\mathrm{APC}^{\mathrm{Min} /+}$ mice. These differences became even more striking at 12 weeks when we could see the first differences in colon tumorigenesis (Fig. 7c). Notably, Bacteroidetes are significantly up-regulated in the stoolassociated microbiota of CRC patients and have been correlated with elevated Th17 in their healthy mucosa (Ahn et al., 2013; Sobhani et al., 2011). Although the fecal microbiota reflects the disease status when comparing CRC patients with healthy controls, several lines of evidences recently showed that the microbiota specifically associated with the mucus layer and with the 
tumor itself differs from the fecal microbiota and might more closely reflect the changes occurring in the tumor microenvironment (Flemer et al., 2017). To understand whether the differences found in the fecal microbiota were mirrored at the tumor site, in addition to the previously described analysis, we sequenced the mucus- and tumor-associated bacteria in 12week-old $\mathrm{APC}^{\mathrm{Min} /+}$ and $\mathrm{APC}^{\mathrm{Min} /+} / \mathrm{C} 3 \mathrm{aR}-/-$ mice. As shown in Fig. 8a, the tumor-and mucusassociated bacterial phyla were strikingly similar between $\mathrm{APC}^{\mathrm{Min} /+}$ and $\mathrm{APC}^{\mathrm{Min} /+} / \mathrm{C} 3 \mathrm{aR}-/-$ mice and were dominated by Firmicutes $(55 \%$ and $54 \%$ in the tumor; $69 \%$ and $65 \%$ in the mucus respectively) followed by Bacteroidetes (17\% and $14 \%$ in the tumor; $26 \%$ and $29 \%$ in the mucus respectively). These results closely mirror the bacterial composition in CRC, where it has been shown that Firmicutes is the predominant phylum in the cancerous tissues followed by Bacteroidetes (Gao et al., 2015). It is worth noting that the bacterial composition in tumor and mucus of the two mouse strains was more similar than that in the stool. These results suggest that the physiologic and metabolic alterations occurring in the tumor microenvironment might represent the main constraint that dictates the specific composition of the microbial community.

\section{Colon tumors of $\mathrm{APC}^{\mathrm{Min} /+} / \mathrm{C} 3 \mathrm{aR}-/-$ mice harbor an $\mathrm{E}$. faecalis strain that supports tumor}

\section{growth}

The results of the metagenomic analysis on tumor- and mucus- associated microbiota showed that among the most represented species in the phylum Firmicutes both in APC ${ }^{\mathrm{Min} /+}$ and $\mathrm{APC}^{\mathrm{Min} /+} / \mathrm{C} 3 \mathrm{aR}-/-$ mice there was $E$. faecalis, which was found up-regulated in the tumors of $\mathrm{APC}^{\mathrm{Min} /+} / \mathrm{C} 3 \mathrm{aR}-/-$ mice compared to the mucus and increased over time in the tumor microenvironment (Fig. 8b-c). E. faecalis is a Gram-positive bacterium that preferentially colonizes the colonic mucosa and has been proposed as a possible CRC driver due to its ability to produce superoxide and hydrogen peroxide that induce DNA damage and support malignant 
transformation (Sears and Garrett, 2014; Wang et al., 2015). To understand the effect of $E$. faecalis on tumor growth, we isolated these species from the tumors of either $\mathrm{APC}^{\mathrm{Min} /+}$ or $\mathrm{APC}^{\mathrm{Min} /+} / \mathrm{C} 3 \mathrm{aR}-/-$ mice: colon tumors were collected and homogenized as described in the experimental procedures, and serial dilutions were plated on tryptic broth (TB) agar plates. Single colonies were picked and plated on fresh agar plates in order to ensure purity and were subsequently characterized by colony PCR and $16 \mathrm{~S}$ sequencing. After identification of $E$. faecalis by $16 \mathrm{~S}$ sequencing, we performed whole genome sequencing (WGS) and compared the genome of the isolates from either $\mathrm{APC}^{\mathrm{Min} /+}$ or $\mathrm{APC}^{\mathrm{Min} /+} / \mathrm{C} 3 \mathrm{aR}-/-$ tumors with the genomes of all known species by using the PhyloPhlAn2 software. This phylogenetic analysis confirmed that the two species were both very closely related to Enterococcus sp_7L76 (Suppl. Figure 4a).

Next, the sequences of the two isolates were scanned for genomic features, including protein coding genes, using the Prokka software, and a pan-genome analysis was carried out using the Roary software to identify genes present in both isolates or specific to each one of them (Page et al., 2015).

As shown in Suppl. Fig. 4b, despite being phylogenetically very closely related, the E. faecalis isolated from $\mathrm{APC}^{\mathrm{Min} /+}(\mathrm{C} 11)$ and $\mathrm{APC}^{\mathrm{Min} /+} / \mathrm{C} 3 \mathrm{aR}-/-(\mathrm{C} 19)$ tumors showed differences in the expression of several genes. In particular, C19 carried genes typically associated with more invasive and more pathogenic strains that were absent from the genome of $\mathrm{C} 11$ and of the deposited E. faecalis (G000210115) (Suppl. Fig. 5a). Of note, C19 but not C11 carried the virulence factor coding gene asal, which is responsible for bacterial aggregation on the surface of host tissues and has been described to be expressed by the E. faecalis strains isolated from the mucosa of IBD patients (Golinska et al., 2013). Further, considering that the production of prooxidative reactive oxygen species (ROS) is well described in E. faecalis and could be relevant 
for its pro-inflammatory activity, we evaluated C11 and C19 for their ability to produce ROS. As shown in Fig. 9a, C19 showed enhanced ROS production. Therefore, we next analyzed whether the two E. faecalis had a different effect on colon tumor growth. To accomplish this, five-weekold $\mathrm{APC}^{\mathrm{Min} /+}$ mice were treated with broad-spectrum antibiotics for one week, then left untreated or administered with $\mathrm{C} 11$ or $\mathrm{C} 19$ as detailed in the experimental procedures and sacrificed at 12 weeks (Fig. 9c). As shown in Fig. 9c, 66.7\% of the mice receiving C19 and 16.7\% receiving C11 showed rectal bleeding throughout the experiment while no bleeding was observed in control mice. Accordingly, the administration of C19 resulted in significantly higher tumor number and load compared to C11 (Figure 9d-e). There were no significant differences in the tumors in the small intestine (Suppl. Fig. 5b-c). We also characterized colon infiltrating immune cells by flow cytometry and found that the administration of C19 was associated with higher infiltration by Th17 and Th1/Th17 cells in the colon lamina propria, however, without reaching statistical significance when compared to mice receiving C11 (Fig. 9f-i). In addition, as previously shown with FMT, we found no differences in immune cell infiltration in the mLN (Suppl. Fig. 5d-f). These results suggest that lack of $\mathrm{C} 3 \mathrm{aR}$, an essential component for anti-microbial functions, promotes the establishment of an inflammatory fecal microbiota that drives immune infiltration in the tumor microenvironment, where more virulent bacteria, such as E. faecalis (C19), are selected and able to persist, further boosting inflammation.

\section{DISCUSSION}

The role of complement in intestinal homeostasis and CRC is not well understood.

Here we report for the first time that downregulation of the receptor for complement anaphylatoxin $\mathrm{C} 3 \mathrm{a}(\mathrm{c} 3 \mathrm{arl})$ and $\mathrm{CpG}$ island methylation occur in $\mathrm{CRC}$. By reverse-translating 
this finding we were able to recapitulate colonic tumorigenesis in APC ${ }^{\mathrm{Min} /+}$, which usually show a prevalence of tumors in the small intestine (Guglietta et al., 2016; Moser et al., 1990). Therefore, by knocking down $\mathrm{C} 3 \mathrm{aR}$ we were able to generate a reproducible mouse model that more closely mirror the tumorigenic process occurring in humans. Furthermore, we found that loss of $\mathrm{C} 3 \mathrm{aR}$ profoundly affects the inflammatory infiltrate of colonic tumors and results in a pro-inflammatory fecal and tumor-associated microbiota. Inactivation of the central component of the complement cascade $\mathrm{C} 3$ was shown to exacerbate chronic intestinal inflammation via upregulation of inflammatory cytokines, demonstrating that activation of the complement cascade is a key regulator of intestinal homeostasis (Elvington et al., 2015). In one of the few prior studies investigating the role of complement in $\mathrm{CRC}$, the authors showed that the complement anaphylatoxin $\mathrm{C} 5 \mathrm{aR}$ exacerbates tumor development in an AOM/DSS model of inflammation-driven CRC, by recruiting IL-1 $\beta$ producing neutrophils (Ning et al., 2015). Significant modulation of the complement system has been also reported in cancer molecular subtype 2 (CMS2) and CMS4 human CRC (Guinney et al., 2015). In addition, a very recent study reported that up-regulation of the complement regulatory protein CD55, which inhibits the central complement component, C3 convertase, correlates with decreased disease-free survival in human CRC (Olcina et al., 2018).

Several mechanisms could potentially mediate C3aR down-regulation or inactivation in human CRC. In this context it is important to note that, while genetic mutations in the complement system as a group occur at a significant higher rate than in any other gene for several cancers, most individual complement genes mutate at a lower rate than many canonical oncogenes and oncosuppressors (Ding et al., 2010; Olcina et al., 2018). Accordingly, we found that in CRC patients as compared to healthy controls there is a significantly higher frequency of C3aR 
methylation occurring in those regions that are likely to result in mRNA expression changes. Therefore, methylation may represent the main cause of $\mathrm{C} 3 \mathrm{aR}$ downregulation in human CRC. Mechanistically we found that lack of C3aR resulted in significant accumulation of Th17 and Th1/Th17 cells in the colon lamina propria and in the tumors. The role of IL17 in CRC is highly debated. Indeed, production of IL-17A has been shown to be important for preserving the integrity of the epithelial barrier (Kumar et al., 2016; Lee et al., 2015). However, data in patients and mouse models of CRC showed that IL17 production by different cell sources promotes exacerbation of the inflammatory process and fosters cancer cell proliferation (Goktuna et al., 2016; Grivennikov et al., 2012; Wang et al., 2014). Furthermore, a recent study by Omenetti and collaborators showed that Th17 cells can be defined by their ability to produce high levels of inflammatory cytokines and by the activation of inflammation-related pathways (Omenetti et al., 2019). Our flow cytometry and RNASeq data clearly show that, besides their pronounced ability to produce IL-17A, the cells enriched in the colon lamina propria and tumors of $\mathrm{APC}$ Min/+ $/ \mathrm{C} 3 \mathrm{aR}-$ /- mice produced significantly higher amount of IFN- $\gamma$ as compared to their counterpart in $\mathrm{APC}^{\mathrm{Min} /+}$ mice. In tumors and colon lamina propria of $\mathrm{APC}^{\mathrm{Min} /+} / \mathrm{C} 3 \mathrm{aR}-/-$ mice, we consistently found up-regulation of several signal transducers and activators of transcription, such as STAT-1 and STAT-4, and increased levels of inflammatory cytokines, such as TNF- $\alpha$, IL-22 and IL-1 $\beta$. The induction of mucosal immune responses is largely dependent on the host microbiota and several reports highlighted the effect of innate immune mechanisms in modifying the gut flora (Fulde et al., 2018; Salzman et al., 2010; Vaishnava et al., 2011). Besides being regarded as an important link between innate and adaptive immune responses, the complement system is fundamentally a first line of defense against pathogens. Moreover, C3a, the ligand of C3aR, has been demonstrated to exert anti-bacterial functions (Nordahl et al., 2004). Despite this evidence, 
there are no studies in the literature evaluating the effect of $\mathrm{C} 3 \mathrm{aR}$ on the gut microbiota. However, Chehoud and collaborators found that genetic ablation and antagonism of C5aR correlated with an inflammatory microbiota in the skin, suggesting that complement anaphylatoxins receptors may also play a role in shaping the gut flora (Chehoud et al., 2013). Consistent with data in literature showing that C3aR-/- mice are unable to efficiently clear Gramnegative bacteria, we found that the fecal microbiota of $\mathrm{APC}^{\mathrm{Min} /+} / \mathrm{C} 3 \mathrm{aR}-/-$ and $\mathrm{C} 3 \mathrm{aR}-/-$ mice was characterized by higher abundance of Gram-negative bacteria such as Bacteroidetes and Proteobacteria (Hollmann et al., 2008; Kildsgaard et al., 2000). This preceded tumorigenesis and was further enhanced during tumor development. The fecal microbiota established in the absence of C3aR was likely the main driver of Th1, Th17 and Th1/Th17 cells in the colon of APC ${ }^{\mathrm{Min} /+}$ mice that received fecal microbiota transplantation from $\mathrm{APC}^{\mathrm{Min} /+} / \mathrm{C} 3 \mathrm{aR}-/-$ mice. Indeed, the tumor- and mucus-associated microbiota were strikingly similar between $\mathrm{APC}{ }^{\mathrm{Min} /+}$ and $\mathrm{APC}^{\mathrm{Min} /+} / \mathrm{C} 3 \mathrm{aR}-/-$ mice. Nevertheless, we report the identification of a strains of E. faecalis, in the tumors of $\mathrm{APC}^{\mathrm{Min} /+} / \mathrm{C} 3 \mathrm{aR}-/-$ mice, that displayed a gene repertoire more typical of proinflammatory and invasive strains of E. faecalis when compared to the same species isolated from $\mathrm{APC}^{\mathrm{Min} /+}$ tumors. A few studies in humans reported significantly higher levels of E. faecalis in CRC patients compared to healthy controls, however the mechanisms linking E. faecalis to CRC remain unclear (Balamurugan et al., 2008; Wang et al., 2012). In our work, when used in single bacteria transfer experiments in vivo, E. faecalis from $\mathrm{APC}^{\mathrm{Min} / \mathrm{+}} / \mathrm{C} 3 \mathrm{aR}-/-$ mice resulted in higher tumor load and number compared to E. faecalis from $\mathrm{APC}^{\mathrm{Min} /+}$ mice. Mechanistically, the small but significant increase in ROS production observed in E. faecalis from $\mathrm{APC}^{\mathrm{Min} /} / \mathrm{C} 3 \mathrm{aR}-/-$ mice could explain the increased tumorigenic potential, therefore confirming previous finding (Huycke et al., 2002; Huycke and Moore, 2002). In addition, the presence of genes associated 
with quorum sensing, such as asa 1, in E. faecalis from $\mathrm{APC}^{\mathrm{Min} /+} / \mathrm{C} 3 \mathrm{aR}-/-$ mice might favor the formation of biofilm-like structures that confer a survival advantage in the highly inflammatory tumor microenvironment.

Based on our findings regarding the role of $\mathrm{C} 3 \mathrm{aR}$ in regulating the microbiome and immune infiltrate during tumor development, it is tempting to speculate that similar mechanisms may be at play in other human cancers and especially in those arising in surfaces exposed to the external environment where innate immune defense mechanisms and microbiome play an important role (Gomes et al., 2014; Janakiram and Rao, 2014; Maru et al., 2014; Senol et al., 2014).

Future studies will be needed to assess the mechanisms responsible for $c 3 a r 1$ methylation and to determine whether $\mathrm{C} 3 \mathrm{aR}$ downregulation could be used as biomarker or exploited for therapeutic purposes.

\section{FIGURE LEGENDS}

\section{Figure 1. C3aR methylation and down-regulation in CRC patients}

(A) $\mathrm{C} 3 \mathrm{aR}$ expression in patients with rectal and colon cancer from 4 independent datasets (TGCA: 22 healthy-55 RC; Skrzypczak cohort: 24 healthy- 45CoAdK; Sebates-Bellver cohort:32 healthy- 25 CoAd; Ki cohort: 41 healthy-76 CoAdK). (B) N shelf, (C) S shore and (D) $\mathrm{N}$ shore methylation of c3arl methylation in patients with CRC. Significance was calculated using t-test $(* \mathrm{p}>0.05 ; * * * * \mathrm{p}>0.0001)$.

Figure 2. Loss of C3aR exacerbate inflammation and tumor development in inflammationdriven CRC

(A) WT and C3aR-/- mice were treated with AOM/DSS and weight loss was monitored every other day. (B) Overall survival in AOM/DSS-treated WT and C3aR-/- mice. (C) Total number 
of tumors in the colon of WT and C3aR-/- mice. (D) Single tumor diameters in WT and C3aR-/mice were measured with a sliding caliper and assigned to the groups $<2 \mathrm{~mm}$ or $>2 \mathrm{~mm}$. (E) Tumor load for each mouse was calculated by adding up individual tumor diameters. Single cell suspensions from mesenteric lymph nodes (mLN) and tumors of WT and C3aR-/- mice were analyzed by flow cytometry. Display of total numbers of $(\mathrm{F})$ myeloid cells $(\mathrm{CD} 11 \mathrm{c} \mathrm{MF}=$ CD11c+ macrophages), (G) Tregs (CD3+ CD4+ CD25+ FoxP3+), and (H) Th1 (CD3+CD4+ IFN $\gamma+)$ cells, Th17 (CD3+CD4+ IL-17A+) cells and Th1/Th17 (CD3+CD4+ IFN- $\gamma+$ IL-17A+) cells in mLN. Total numbers of (I) myeloid cells, (K) Tregs, and (J) Th1, Th17 and Th1/Th17 in tumors as gated in F-H. Results are pooled from two independent experiments with a minimum of 8 mice/group). Significance was calculated in A, C and E using t-test and in B using MantelCox test; 2-way ANOVA with Bonferroni post-test was used in panel D and F-L $(* \mathrm{p}<0.05$; ** $\mathrm{p}<0.01 ; * * * \mathrm{p}<0.001)$

Figure 3. Loss of C3aR switches tumorigenesis from small intestine to colon in $\mathrm{APC}^{\mathrm{Min} /+}$ and mice and promotes increased infiltration with Th1/Th17

(A) Tumor number in the colon of $\mathrm{APC}^{\mathrm{Min} /+}$ and $\mathrm{APC}^{\mathrm{Min} /+} / \mathrm{C} 3 \mathrm{aR}-/-$ mice was assessed starting at 5 weeks until 28 weeks of age. (B) Display of an example of tumor number and distribution in the colon of $\mathrm{APC}^{\mathrm{Min} /+}$ and $\mathrm{APC}^{\mathrm{Min} /+} / \mathrm{C} 3 \mathrm{aR}-/-$ mice. Single cell suspensions from colon lamina propria (cLP) $\mathrm{APC}^{\mathrm{Min} /+}$ and $\mathrm{APC}^{\mathrm{Min} /+} / \mathrm{C} 3 \mathrm{aR}-/-$ mice were analyzed by FACS and total number of (C) CD4+T cells, (D) Th17 cells, (E) Th1 cells, (F) Th1/Th17 cells, (G), CD8+ T cells (H) Tc cells $(\mathrm{CD} 3+\mathrm{CD} 8+\mathrm{IFN}-\gamma+)$ were gated and calculated as for Fig. 2. In panel A significance was calculated by using 2-way ANOVA with Bonferroni post-test $(* \mathrm{p}<0.05 ; * * * \mathrm{p}<0.001)$ and a minimum of 10 mice/group was used. In panels $\mathrm{C}-\mathrm{H}$ a minimum of 7 animals/group was used and significance was calculated using unpaired t-test (ns= not significant; $* \mathrm{p}<0.05 ; * * \mathrm{p}<0.01)$. 
Figure 4. Loss of C3aR results in transcriptional up-regulation of innate and adaptive immune pathways in the healthy distal colon of $\mathrm{APC}^{\mathrm{Min} /+} / \mathrm{C3aR}-/-$ mice.

(A) Heatmap from (row-wise z-transformed) log counts per million values, using data from distal colon of indicated mouse strains and all genes that are significant at 5\% FDR in at least one contrast. Rows represent genes, and columns represent individual samples. Each row (gene) is ztransformed to have mean zero and standard deviation one. The heatmap also includes column annotation labels indicating the mouse strain for each sample. (B) Visualization of the geneassociated Gene Ontology (GO) biological processes in healthy colon. (C) Volcano plot illustrating the magnitude of fold change for all genes differentially expressed in the distal colon of $\mathrm{APC}^{\mathrm{Min} /+} \mathrm{C} 3 \mathrm{aR}-/-$ vs $\mathrm{APC}^{\mathrm{Min} /+}$ mice $(\mathrm{n}=4)$. Representative significantly up-regulated and down-regulated genes belonging to the GO biological processes shown in B are highlighted in yellow.

Significance was calculated using the edgeR function decideTestsDGE with BenjaminiHochberg correction for false discovery rate (FDR); a default FDR threshold of 0.05 and a $\log 2$ fold change (log2FC) threshold of 0.6 were applied.

\section{Figure 5. APC ${ }^{\mathrm{Min} /+} / \mathrm{C} 3 \mathrm{aR}-/-$ polyps show an enrichment of inflammatory pathways}

(A) Heatmap from log counts per million values using data from colon polyps from APC ${ }^{\mathrm{Min} /+}$ and $\mathrm{APC}^{\mathrm{Min} /+} / \mathrm{C} 3 \mathrm{aR}-/-$ mice. (B) Visualization of the gene-associated Gene Ontology (GO) biological processes in the polyps. (C) Volcano plot illustrating the magnitude of fold change for all genes differentially expressed in the polyps of $\mathrm{APC}^{\mathrm{Min} /+} \mathrm{C} 3 \mathrm{aR}-/-\quad$ vs $\mathrm{APC}^{\mathrm{Min} /+}$ mice $(\mathrm{n}=4)$. Representative significantly up-regulated and down-regulated genes belonging to the GO biological processes shown in B are highlighted in yellow. Vertical and horizontal red dotted lines indicate the threshold. Significance was calculated using the edgeR function 
decideTestsDGE with Benjamini-Hochberg correction for false discovery rate (FDR); a default FDR threshold of 0.05 and a $\log 2$ fold change $(\log 2 \mathrm{FC})$ threshold of 0.6 were applied.

Figure 6. Transplantation of the $\mathrm{APC}^{\mathrm{Min} /+} / \mathrm{C} 3 \mathrm{aR}-/-$ microbiota transfers colon tumorigenesis to $\mathrm{APC}^{\mathrm{Min} /+}$ mice

(A) 5-week-old APC ${ }^{\mathrm{Min} /+}$ mice (recipients) $(\mathrm{n}=22)$ were treated for 1 week with broad spectrum antibiotics (abx). $48 \mathrm{~h}$ after antibiotics treatment, the recipient mice were transplanted via oral gavage with the gut microbiota of 12 -week-old $\mathrm{APC}^{\mathrm{Min} /+}$ or $\mathrm{APC}^{\mathrm{Min} /+} / \mathrm{C} 3 \mathrm{aR}-/-$ mice (donors) for 3 consecutive days and again once/week for 7 weeks. (B) Tumor count in the colon of recipient mice was performed at the end of the experiment. (C-H) Flow cytometry analysis of cLP infiltrating lymphocytes showing total cell number of (C) CD4+T cells, (D) Th1 cells, (E) Th17 cells, (F) Th1/17 cells, (G) CD8+ T cells and (H) Tc cells as calculated in Fig. 2. Shown are the results of two independent experiments with a minimum of 5 mice/group. Significance was calculated using unpaired t-test $(* * \mathrm{p}<0.01 ; * * * \mathrm{p}<0.001 ; * * * * \mathrm{p}<0.0001)$.

\section{Figure 7. Loss of C3aR affects the composition of the fecal microbiota in $\mathrm{APC}^{\mathrm{Min} /{ }^{+}}$mice}

Bacterial DNA was extracted from the feces of 8-and 12-week-old $\mathrm{APC}^{\mathrm{Min} /+}$ and $\mathrm{APC}^{\mathrm{Min} /+} / \mathrm{C} 3 \mathrm{aR}-$ /- mice, and bacterial profiling was performed by sequencing the V5-V6 hypervariable of 16S rDNA using Illumina MySeq platform. (A) Plots showing alpha diversity evaluated by observed ASV, Faith and Shannon Index in 8-and 12-week-old mice. (B) PCoA showing the beta diversity evaluated by the three inferred Beta Diversity metrics (weighted UniFrac, unweighted UniFrac and Bray-Curtis) in 8- and 12-week-old mice. (C) Doughnut charts showing phylum abundance at 8 and 12 weeks. Significance was calculated in A using Kruskal-Wallis test followed by a pairwise Wilcoxon as post-hoc test; in B using PERMANOVA test and in C using DESeq Rpackage. $(* * \mathrm{p}<0.01)$ 


\section{Figure 8. Impact of C3aR on tumor- and mucus-associated microbiota species}

Bacterial DNA was extracted from colonic tumors and mucus of 12 -week-old $\mathrm{APC}^{\mathrm{Min} /+}$ and $\mathrm{APC}^{\mathrm{Min} /+} / \mathrm{C} 3 \mathrm{aR}-/-$ mice and metagenomic analysis was performed. (A) Doughnut charts showing the bacterial composition of mucus and colon of 12-week-old $\mathrm{APC}^{\mathrm{Min} /+}$ and $\mathrm{APC}$ Min/+ $/ \mathrm{C} 3 \mathrm{aR}-/-$ mice. (B) Bacterial species up-or down-regulated in the tumor vs mucus in APC ${ }^{\mathrm{Min} /} / \mathrm{C} 3 \mathrm{aR}-/-$ mice. (C) Bacterial species up-and down-regulated in tumors of 12- vs 16-week-old $\mathrm{APC}^{\mathrm{Min} /+} / \mathrm{C} 3 \mathrm{aR}-/-$ mice. Significance was calculated in A and B by DESeq R-package; in C using 1-way Anova with Bonferroni post-test.

Figure 9. Colon tumors of $\mathrm{APC}^{\mathrm{Min} /+} / \mathrm{C} 3 \mathrm{aR}-/-$ mice harbor a more inflammatory $\mathrm{E}$. faecalis strain

(A) $1.2 \times 10^{8} \mathrm{C} 11$ or $\mathrm{C} 19$ bacteria cell cultures were used to assess ROS production with the Amplex Red Hydrogen Peroxide/Peroxidase Assay Kit. Measurements were taken after 60 min of incubation.

(B) 5-week-old APC ${ }^{\mathrm{Min} /+}$ mice $(\mathrm{n}=6)$ were treated for one week with broad-spectrum antibiotics and subsequently administered with $10^{\wedge} 9 \mathrm{CFU}$ of $E$. faecalis isolated from $\mathrm{APC}^{\mathrm{Min} /+}(\mathrm{C} 11)$ or $\mathrm{APC}^{\mathrm{Min} /+} / \mathrm{C} 3 \mathrm{aR}-/-(\mathrm{C} 19)$ mice or left untreated for 7 weeks. (C) Percentage of mice with rectal bleeding in each group. (D) Tumor number and (E) tumor load in the colon of the mice was evaluated at the end of the experiment. (F) Th1 cells, (G) Th17 cells, (H) Th1/17 cells and (I) Tc cells in the colon lamina propria of tumor-bearing mice were assessed by flow cytometry. Significance in panel A was calculated using unpaired t-test; in C-I using 1-way Anova with Bonferroni post-test $(* \mathrm{p}<0.05 ; * * \mathrm{p}<0.01 ; * * * \mathrm{p}<0.001)$.

\section{METHODS}

\section{Animals}


$\mathrm{C} 57 \mathrm{BL} / 6 \mathrm{~J}-\mathrm{ApcMin} / \mathrm{J}$ (referred to as $\mathrm{APC}^{\mathrm{Min} /+}$ ) and C57BL/6J (referred to as WT) mice were bred and maintained in our SPF (Specific Pathogen Free) animal facility at European Institute of Oncology and at the Medical University of South Carolina. C3aR-/- mice on C57BL/6J background were a kind gift from Dr. Bao Lu and Dr. Carl Atkinson. APC ${ }^{\mathrm{Min} /+} / \mathrm{C} 3 \mathrm{aR}-/-$ mice were generated by crossing C57BL/6J-ApcMin/J with C3aR-/- mice in our animal facilities. All animal experiments were performed in accordance with the guidelines established in the Principles of Laboratory Animal Care (directive 86/609/EEC) and approved by Italian Ministry of Health and under approved protocols by the Institutional Animal Care and Use Committee at MUSC (IACUC-2017-00165; IACUC-2020-01022)

\section{AOM/DSS}

Twelve-week-old WT and C3aR-/- mice were intraperitoneally injected with $10 \mathrm{mg} / \mathrm{Kg}$ of azoxymethane (AOM; Sigma-Aldrich). After 7 days, mice were administered with 1.5\% (w/v) DSS (TdB Consultancy) in their drinking water for 1 week followed by 2 weeks of recovery. DSS/recovery cycles were repeated three times as previously described (Neufert et al., 2007). Mice were weighed every other day. At the end of the experiment, mice were sacrificed, tumors in the colon were counted and their diameter measured using a sliding caliper. Tumor load for each mouse was calculated by adding the average diameter of all tumors.

\section{Spontaneous colonic tumorigenesis and FACS analysis of infiltrating immune cells}

$\mathrm{APC}^{\mathrm{Min} /+}$ and $\mathrm{APC}^{\mathrm{Min} /+} / \mathrm{C} 3 \mathrm{aR}-/-$ mice were sacrificed at different time points starting at the age of 5 weeks until 28 weeks and tumors in the colon were counted. Colon, tumors and mesenteric lymph nodes $(\mathrm{mLN})$ were used to characterize the immune cells by FACS. Single cell suspensions were prepared from $\mathrm{mLN}$ following standard protocols. Colon lamina propria cells were isolated as previously described with minor modifications (Lefrancois and Lycke, 2001). 
For isolation of tumor-associated immune cells, colon polyps were shaken in PBS, $1 \%$ BSA, 10 mM EDTA in order to remove epithelial cells, and further digested for 30 minutes at $37^{\circ} \mathrm{C}$ with Collagenase VIII (Sigma-Aldrich) in complete medium with shaking.

For flow cytometry staining, cells were incubated with anti-FcR antibody (clone 24G2) and stained with the following surface antibodies: anti-CD45.2 (clone 104, eBioscience), Ly6G (clone 1A8), CD3 (clone 17A2, eBioscience), Ly6C (clone AL-21), CD11b (clone M1/70), CD4 (cloneRM4-5), CD8a (53-6-7), B220 (clone RA3-6B2), I-A/I-E (clone M5/114.15.2), CD11c (clone HL3), F4/80 (MB8, eBioscience), CD103 (clone 2E7), CD25 (clone PC61), anti- IFN- $\gamma$ (clone XMG1.2), anti-IL-17A (clone TC11-18H10), anti-FoxP3 (clone FJK-16s eBioscience). For cytokine staining cells were permeabilized with Cytofix/Cytoperm buffer (BD) according to manufacturer instructions. For Foxp3 staining the permeabilization was performed using the FoxP3 permeabilization buffer (eBioscience). All antibodies were purchased from BD Pharmingen unless otherwise specified. Samples were acquired with FACSCanto II or Fortessa LSR (BD Bioscience) and analyzed with FlowJo software (TreeStar).

\section{Fecal microbiota transplantation and gavage with E. faecalis}

For fecal microbiota transplantation (FMT), fecal material was obtained from 12-week-old $\mathrm{APC}^{\mathrm{Min} /+}$ and $\mathrm{APC}^{\mathrm{Min} /+} / \mathrm{C} 3 \mathrm{aR}-/-$ donor mice. Briefly, fecal pellet and cecal contents were harvested from the mice, dissolved in sterile PBS at $100 \mathrm{mg} / \mathrm{ml}$, passed through a $70-\mu \mathrm{m}$ strainer in order to eliminated insoluble debris, and frozen in Columbia broth with $20 \%$ glycerol. At the time of administration, aliquots were thawed, centrifuged to eliminate the glycerol-containing medium and resuspended at $100 \mathrm{mg} / \mathrm{ml}$ for gavage. This procedure allowed us to use the same material throughout the experiment, thereby avoiding confounding effects due to fecal and mucus material coming from different animals. Five-week-old $\mathrm{APC}^{\mathrm{Min} /+}$ mice were used as FMT 
recipient Recipient mice were treated for one week with the broad-spectrum antibiotics in the drinking water, rested for $48 \mathrm{~h}$ with water without antibiotics, followed by gavage with $200 \mu \mathrm{l}$ /mouse of the previously prepared fecal and mucus material for 3 consecutive days in the first week and once a week for the next 6 weeks. For E. faecalis administration, we followed a treatment scheme similar to the one described for FMT. E. faecalis isolated from APC ${ }^{\mathrm{Min} /+}$ and $\mathrm{APC}^{\mathrm{Min} /+} / \mathrm{C} 3 \mathrm{aR}-/-$ mice were grown in aerobic condition at $37^{\circ} \mathrm{C}$ with terrific broth (TB). CFUs were determined along the growth phase from serial dilution plated on TB plates at $37^{\circ} \mathrm{C}$ for 24 h. Next, single colonies were grown overnight in TB broth, restarted at $\mathrm{OD}_{600}$ of 0.05 in fresh $\mathrm{TB}$ and grown to $\mathrm{OD}_{600}$ of $0.8 \cdot 10^{9} \mathrm{CFU}$ from each bacteria culture were administered via oral gavage to each mouse and after the first 3 consecutive administrations, we performed 2 gavages/week for the remaining 6 weeks. At the end of the treatment animals were sacrificed, colon tumors counted, and single cell suspensions were prepared from colon and mLN.

\section{Fecal, mucus and tumor microbiota profiling}

Fecal pellets were harvested from 8- and 12-week-old $\mathrm{APC}^{\mathrm{Min}}$ and $\mathrm{APC}^{\mathrm{Min} /+} / \mathrm{C} 3 \mathrm{aR}-/-$ mice and used to extract DNA with G'NOME DNA isolation kit (MP) following a published protocol (Furet et al., 2009). V5-V6 hypervariable regions of bacterial 16S rRNA gene were amplified and processed with a modified version of the Nextera protocol (Manzari et al., 2014). The obtained metabarcoding libraries were sequenced by using the MiSeq Illumina platform with a 2x250 paired end (PE) approach. Metagenomic amplicons were analyzed by applying the BioMaS pipeline (Fosso et al., 2015): (i) The paired-end reads were merged into consensus sequences using Flash (Magoc and Salzberg, 2011) and subsequently dereplicated as previously described (Edgar, 2010) maintaining the consensus sequence; (ii) The remaining non overlapping PE reads were considered for further analysis only if after the low-quality region trimming 
(Phred quality cut-off $=25$ ) both read ends were $\geq 50$ bp long; (Mariathasan et al.) Both the merged sequences and the unmerged reads were matched against the RDP (Ribosomal Database Project) database (release 10.29)(Cole et al., 2009) by Bowtie2 (Langmead and Salzberg, 2012). The mapping data were filtered according to two parameters: identity percentage $(\geq 97 \%)$ and query coverage $(\geq 70 \%)$; (iv) Finally, all mapped reads fulfilling the settled filters were taxonomically annotated using the Tango tool (Alonso-Alemany et al., 2014). Assigned genera were filtered considering as present only the ones for which at least five reads per samples were present. The read counts were normalized using an approach similar to the RPKM (Reads per kilo-base per million): normalized count $=$ assigned reads / (total assigned reads at the rank level/1,000,000). Significant differences at the genus and species level were calculated with the DESeq R-package (Anders and Huber, 2010). A tree representing the phylogenetic relationship between the Amplicon Sequence Variants (ASV) was produced by using the QIIME1 package (Caporaso et al., 2010). The rarefaction curves were inferred and plotted by using an in house developed R script relying on the rarefy function of the vegan package. Alpha and Beta diversity analysis were performed using the phyloseq R (McMurdie and Holmes, 2013). In particular, the observed ASVs, the Shannon and the Faith Indexes were used as richness and alpha diversity measures. The weighted and unweighted UniFrac and the Bray-Curtis metrics were used for the Beta diversity inference (Chang et al., 2011). Difference in the inferred alpha diversity indices were measured by using the Kruskal-Wallis test followed by a pairwise Wilcoxon as post-hoc test (p-values corrected by using the Benjamin-Hochberg $(\mathrm{BH})$ procedure). The PERMANOVA test was used to compare groups in beta diversity data, using 999 permutations.

To isolate bacterial DNA from mucus scraped from the colon we used the same protocol used to isolate bacterial DNA from the feces. For the isolation of tumor-associated bacteria, tumors were 
homogenized in sterile phosphate buffered saline solution (PBS), centrifuged, and both supernatants and pellets were subjected to depletion of host DNA by using the QIAamp DNA Microbiome kit (Qiagen) before proceeding with bacterial DNA extraction with the same protocol described for feces. Sequencing libraries were prepared using the Nextera XT Library Preparation kit (Illumina) following the manufacturer's guidelines. Sequencing was performed on HiSeq 2500 platform (Illumina).

\section{Colony PCR}

Bacteria associated to mucus and feces were plated on agar plates and screening of different colonies was performed using colony PCR. Briefly, cells from a single colony were picked from agar plates by using a sterile pipette tip and resuspended into lysis buffer (Tris/EDTA, $0.2 \%$ SDS, and $10 \mathrm{mM}$ EDTA). The lysate was then centrifuged, and the supernatant was collected and used as PCR template. PCR amplification was performed on the 16SrRNA amplifying V1V4 with $\quad 28 \mathrm{~F} \quad\left(5^{\prime}\right.$-GAGTTTGATCNTGGCTCAG-3'), $\quad 907 \mathrm{R} \quad$ (5'CCGTCAATTCMTTTRAGTTT-3') and V5-V7 with 1392R (5'-ACGGGCGGTGTGTRC-3'), 926F (5'-AAACTYAAAKGAATTGACGG-3'). PCRs were performed with Phusion HighFidelity DNA Polymerase (2 U/ $\mu \mathrm{L})$ (New England Biolabs) in a total volume of $50 \mu \mathrm{l}$. Each cycle consisted of $60 \mathrm{~s}$ at $98{ }^{\circ} \mathrm{C}, 45 \mathrm{~s}$ at $63{ }^{\circ} \mathrm{C}$, and $60 \mathrm{~s}$ at $72{ }^{\circ} \mathrm{C}$, with a final extension of 5 min. The PCR products were subjected to $1 \%$ agarose gel electrophoresis for analysis and purified with QIAquick PCR Purification Kit (Qiagen) according to the manufacturer's protocol.

Whole genome sequencing and phylogenetic analysis of $E$. faecalis from $\mathrm{APC}^{\mathrm{Min} /+}$ and $\mathrm{APC}^{\mathrm{Min} /+} / \mathrm{C3aR}-/-$ mice 
The phylogenetic tree for E. faecalis was reconstructed by considering a set of 100 reference genomes retrieved from GeneBank for the E. faecalis species and the two isolates C11 (E. faecalis $\mathrm{APC}^{\mathrm{Min} /+}$ ) and $\mathrm{C} 19$ (E. faecalis $\left.\mathrm{APC}^{\mathrm{Min} /+} / \mathrm{C} 3 \mathrm{aR}-/-\right)$. The phylogenetic analysis was performed using the latest implementation of PhyloPhlAn (Segata et al., 2013) using the "diversity low" parameter and the 400 PhyloPhlAn universal protein markers. The genes present in $\mathrm{C} 19$ and absent in C11 were classified using KEGG pathway analysis.

\section{Reactive oxygen species (ROS) production by $E$. faecalis}

E. faecalis isolated from $\mathrm{APC}^{\mathrm{Min} /+}$ and $\mathrm{APC}^{\mathrm{Min} /+} / \mathrm{C} 3 \mathrm{aR}-/-$ mice were grown in aerobic conditions at $37^{\circ} \mathrm{C}$ in TB. Single colonies of both E. faecalis were grown until the stationary phase. As template for ROS detection, the culture was centrifuged at $13.000 \mathrm{rpm}$ for 2 minutes and the supernatants were filtered and collected. Alternatively, to start the reaction, $1.2 \times 10^{8}$ bacteria cell cultures (bacteria cells plus supernatant) were added to the plate. The Amplex Red Hydrogen Peroxide/Peroxidase Assay Kit (Invitrogen) was used to detect ROS production following manufacturer's instructions. All the measurements were performed in 96-well plates, using GloMax® Discover Microplate Reader (Promega) equipped for excitation at $540 \mathrm{~nm}$ and detection at 590. Measurements were taken after 60 minutes of incubation.

\section{RNA-Seq analysis of colon and colonic tumors}

For RNASeq analysis, 12-week-old $\mathrm{APC}^{\mathrm{Min} /+}$, WT, C3aR-/- and $\mathrm{APC}^{\mathrm{Min} /+} / \mathrm{C} 3 \mathrm{aR}-/-$ mice (4 mice/group) were sacrificed. The proximal (first $3 \mathrm{~cm}$ adjacent to the caecum) and distal colon (the final $3.5 \mathrm{~cm}$ adjacent to the rectum) and the single tumors were immediately preserved in 2 $\mathrm{ml}$ of RNAlater stabilization solution (Qiagen) according to manufacturer instructions and stored at $-20^{\circ} \mathrm{C}$. For RNA extraction, tumors and colons were homogenized in Trizol (500 ul/50 mg weight), centrifuged at $13000 \mathrm{rpm}$, the supernatant was loaded on Qiagen Mini Kit columns and 
treated as indicated in the manufacturer instructions. RNA concentration was quantified by Nanodrop and quality and integrity were evaluated by using a bioanalyzer (Agilent Technologies). Only samples with a RIN>8 were used for downstream applications.

Briefly, $1 \mu \mathrm{g}$ of RNA was used to prepare cDNA with the TruSeq RNA kit following the recommendations for low sample preparation protocol (Illumina). Samples were sequenced on an Illumina MiSeq instrument at a depth of $35 \times 10^{\wedge} 6$ reads per sample. Reads in FASTQ format were quantified at the gene level using featureCounts and the count table was delivered to edgeR for the differential expression analysis using the GLM functionality (Liao et al., 2014; McCarthy et al., 2012). GO analysis was conducted to identify DEG at the biologically functional level. The identified DEGs were uploaded to the online software Advaita Bioinformatics, which was used to integrate functional genomic annotations.

A false discovery rate (FDR) cutoff of $5 \%$ and minimum fold change of $1.5(\log 2 \mathrm{FC}=0.6)$ was applied to determine differential expression.

RNASeq data are deposited on the ArrayExpress website (accession number: E-MTAB-8500).

\section{Analysis of C3aR methylation and mutations in patients with CRC.}

Data on C3aR expression were obtained from the R2 Genomics Analysis and Visualization Platform (http://r2.amc.nl) or TCGA database. C3aR expression data were plotted with PRISM (GraphPad Software). Data on C3aR methylation were obtained from the human pan-cancer methylation database (MethHC, http://methhc.mbc.nctu.edu.tw/php/index.php) (Huang et al., 2015).

\section{Statistical analysis}

Data were analyzed for normal distribution before performing statistical analyses. Values are presented as means \pm standard error mean (SEM) of multiple individual experiments, each 
carried out at least in triplicate, or as means \pm SEM of replicates in a representative experiment. Comparison between two groups was determined by the Student's t test or Mann-Whitney test. Comparison of multiple groups was carried out by one-way or two-way ANOVA followed by Bonferroni post-test correction using GraphPad Prism software version 8 as indicated in the figure legends. All statistical tests were two-sided, and $P<0.05$ was considered statistically significant, unless otherwise specified.

\section{COMPETING INTERESTS}

The authors have declared that no conflict of interest exists.

ACKNOWLEDGMENTS. The authors wish to acknowledge Roger Johnson for manuscript editing; Dr. Carl Atkinson and Dr. Stephen Tomlinson for providing essential reagents and mice; Dr. Luca Rotta at the IEO Genomics Unit for assistance with RNA sequencing and Federica Armanini for assistance with tumor-associated microbiota sequencing; Dr. Maria Rescigno for AIRC and ERC funding acquisition; American Cancer Society-Institutional Research Grant, AIRC and Fondazione Umberto Veronesi and AIRC fellowship to S.G..

\section{AUTHOR CONTRIBUTION}

S.G. conceived the study and the experimental setup, performed and analyzed experiments and wrote the manuscript with input from all authors; C.K. performed experiments and analysis and wrote the manuscript; S.C. helped with isolation and in vitro testing of bacteria; L.M.W., M.D.R. and G.H. performed analysis of RNASeq data; B.F, G.P. and M.M. performed microbiota sequencing and analysis; E.M. assisted with mouse experiments; S.E.A. gave input for 
microbiota experiments; N.S., and F.A. performed analysis of tumor-associated microbiota and whole genome sequencing of bacterial strains.

\section{REFERENCES}

Ahn, J., Sinha, R., Pei, Z., Dominianni, C., Wu, J., Shi, J., Goedert, J. J., Hayes, R. B., and Yang,

L. (2013). Human gut microbiome and risk for colorectal cancer. J Natl Cancer Inst 105, 19071911.

Alonso-Alemany, D., Barre, A., Beretta, S., Bonizzoni, P., Nikolski, M., and Valiente, G. (2014). Further steps in TANGO: improved taxonomic assignment in metagenomics. Bioinformatics 30, 17-23.

Amicarella, F., Muraro, M. G., Hirt, C., Cremonesi, E., Padovan, E., Mele, V., Governa, V., Han, J., Huber, X., Droeser, R. A., et al. (2017). Dual role of tumour-infiltrating T helper 17 cells in human colorectal cancer. Gut 66, 692-704.

Anders, S., and Huber, W. (2010). Differential expression analysis for sequence count data. Genome Biol 11, R106.

Arbore, G., West, E. E., Spolski, R., Robertson, A. A. B., Klos, A., Rheinheimer, C., Dutow, P., Woodruff, T. M., Yu, Z. X., O'Neill, L. A., et al. (2016). T helper 1 immunity requires complement-driven NLRP3 inflammasome activity in CD4(+) T cells. Science 352, aad1210.

Arnold, M., Sierra, M. S., Laversanne, M., Soerjomataram, I., Jemal, A., and Bray, F. (2017). Global patterns and trends in colorectal cancer incidence and mortality. Gut 66, 683-691. 
Arthur, J. C., Gharaibeh, R. Z., Muhlbauer, M., Perez-Chanona, E., Uronis, J. M., McCafferty, J., Fodor, A. A., and Jobin, C. (2014). Microbial genomic analysis reveals the essential role of inflammation in bacteria-induced colorectal cancer. Nat Commun 5, 4724.

Balamurugan, R., Rajendiran, E., George, S., Samuel, G. V., and Ramakrishna, B. S. (2008).

Real-time polymerase chain reaction quantification of specific butyrate-producing bacteria, Desulfovibrio and Enterococcus faecalis in the feces of patients with colorectal cancer. J Gastroenterol Hepatol 23, 1298-1303.

Burtin, F., Mullins, C. S., and Linnebacher, M. (2020). Mouse models of colorectal cancer: Past, present and future perspectives. World J Gastroenterol 26, 1394-1426.

Caporaso, J. G., Kuczynski, J., Stombaugh, J., Bittinger, K., Bushman, F. D., Costello, E. K., Fierer, N., Pena, A. G., Goodrich, J. K., Gordon, J. I., et al. (2010). QIIME allows analysis of high-throughput community sequencing data. Nat Methods 7, 335-336.

Cash, H. L., Whitham, C. V., Behrendt, C. L., and Hooper, L. V. (2006). Symbiotic bacteria direct expression of an intestinal bactericidal lectin. Science $313,1126-1130$.

Chang, Q., Luan, Y., and Sun, F. (2011). Variance adjusted weighted UniFrac: a powerful beta diversity measure for comparing communities based on phylogeny. BMC Bioinformatics 12 , 118.

Chehoud, C., Rafail, S., Tyldsley, A. S., Seykora, J. T., Lambris, J. D., and Grice, E. A. (2013). Complement modulates the cutaneous microbiome and inflammatory milieu. Proc Natl Acad Sci U S A 110, 15061-15066.

Cole, J. R., Wang, Q., Cardenas, E., Fish, J., Chai, B., Farris, R. J., Kulam-Syed-Mohideen, A. S., McGarrell, D. M., Marsh, T., Garrity, G. M., and Tiedje, J. M. (2009). The Ribosomal 
Database Project: improved alignments and new tools for rRNA analysis. Nucleic Acids Res 37, D141-145.

Coleman, O. I., Lobner, E. M., Bierwirth, S., Sorbie, A., Waldschmitt, N., Rath, E., Berger, E., Lagkouvardos, I., Clavel, T., McCoy, K. D., et al. (2018). Activated ATF6 Induces Intestinal Dysbiosis and Innate Immune Response to Promote Colorectal Tumorigenesis. Gastroenterology $155,1539-1552$ e 1512.

de Souza, P. R., Guimaraes, F. R., Sales-Campos, H., Bonfa, G., Nardini, V., Chica, J. E. L., Turato, W. M., Silva, J. S., Zamboni, D. S., and Cardoso, C. R. B. (2018). Absence of NOD2 receptor predisposes to intestinal inflammation by a deregulation in the immune response in hosts that are unable to control gut dysbiosis. Immunobiology 223, 577-585.

Dejea, C. M., Fathi, P., Craig, J. M., Boleij, A., Taddese, R., Geis, A. L., Wu, X., DeStefano Shields, C. E., Hechenbleikner, E. M., Huso, D. L., et al. (2018). Patients with familial adenomatous polyposis harbor colonic biofilms containing tumorigenic bacteria. Science 359, $592-597$.

Ding, L., Wendl, M. C., Koboldt, D. C., and Mardis, E. R. (2010). Analysis of next-generation genomic data in cancer: accomplishments and challenges. Hum Mol Genet 19, R188-196.

Edgar, R. C. (2010). Search and clustering orders of magnitude faster than BLAST. Bioinformatics 26, 2460-2461.

Elvington, M., Schepp-Berglind, J., and Tomlinson, S. (2015). Regulation of the alternative pathway of complement modulates injury and immunity in a chronic model of dextran sulphate sodium-induced colitis. Clin Exp Immunol 179, 500-508. 
Flemer, B., Lynch, D. B., Brown, J. M., Jeffery, I. B., Ryan, F. J., Claesson, M. J., O'Riordain, M., Shanahan, F., and O'Toole, P. W. (2017). Tumour-associated and non-tumour-associated microbiota in colorectal cancer. Gut 66, 633-643.

Fodde, R., Kuipers, J., Rosenberg, C., Smits, R., Kielman, M., Gaspar, C., van Es, J. H., Breukel, C., Wiegant, J., Giles, R. H., and Clevers, H. (2001). Mutations in the APC tumour suppressor gene cause chromosomal instability. Nat Cell Biol 3, 433-438.

Fosso, B., Santamaria, M., Marzano, M., Alonso-Alemany, D., Valiente, G., Donvito, G., Monaco, A., Notarangelo, P., and Pesole, G. (2015). BioMaS: a modular pipeline for Bioinformatic analysis of Metagenomic AmpliconS. BMC Bioinformatics 16, 203.

Fulde, M., Sommer, F., Chassaing, B., van Vorst, K., Dupont, A., Hensel, M., Basic, M., Klopfleisch, R., Rosenstiel, P., Bleich, A., et al. (2018). Neonatal selection by Toll-like receptor 5 influences long-term gut microbiota composition. Nature 560, 489-493.

Furet, J. P., Firmesse, O., Gourmelon, M., Bridonneau, C., Tap, J., Mondot, S., Dore, J., and Corthier, G. (2009). Comparative assessment of human and farm animal faecal microbiota using real-time quantitative PCR. FEMS Microbiol Ecol 68, 351-362.

Gao, Z., Guo, B., Gao, R., Zhu, Q., and Qin, H. (2015). Microbiota disbiosis is associated with colorectal cancer. Front Microbiol 6, 20.

Garrett, W. S., Lord, G. M., Punit, S., Lugo-Villarino, G., Mazmanian, S. K., Ito, S., Glickman, J. N., and Glimcher, L. H. (2007). Communicable ulcerative colitis induced by T-bet deficiency in the innate immune system. Cell 131, 33-45.

Goktuna, S. I., Shostak, K., Chau, T. L., Heukamp, L. C., Hennuy, B., Duong, H. Q., Ladang, A., Close, P., Klevernic, I., Olivier, F., et al. (2016). The Prosurvival IKK-Related Kinase 
IKKepsilon Integrates LPS and IL17A Signaling Cascades to Promote Wnt-Dependent Tumor Development in the Intestine. Cancer Res 76, 2587-2599.

Golinska, E., Tomusiak, A., Gosiewski, T., Wiecek, G., Machul, A., Mikolajczyk, D., Bulanda, M., Heczko, P. B., and Strus, M. (2013). Virulence factors of Enterococcus strains isolated from patients with inflammatory bowel disease. World J Gastroenterol 19, 3562-3572.

Gomes, M., Teixeira, A. L., Coelho, A., Araujo, A., and Medeiros, R. (2014). The role of inflammation in lung cancer. Adv Exp Med Biol 816, 1-23.

Grivennikov, S. I., Wang, K., Mucida, D., Stewart, C. A., Schnabl, B., Jauch, D., Taniguchi, K., Yu, G. Y., Osterreicher, C. H., Hung, K. E., et al. (2012). Adenoma-linked barrier defects and microbial products drive IL-23/IL-17-mediated tumour growth. Nature 491, 254-258.

Guglietta, S., Chiavelli, A., Zagato, E., Krieg, C., Gandini, S., Ravenda, P. S., Bazolli, B., Lu, B., Penna, G., and Rescigno, M. (2016). Coagulation induced by C3aR-dependent NETosis drives protumorigenic neutrophils during small intestinal tumorigenesis. Nat Commun 7, 11037.

Guinney, J., Dienstmann, R., Wang, X., de Reynies, A., Schlicker, A., Soneson, C., Marisa, L., Roepman, P., Nyamundanda, G., Angelino, P., et al. (2015). The consensus molecular subtypes of colorectal cancer. Nat Med 21, 1350-1356.

Haigis, K. M., Hoff, P. D., White, A., Shoemaker, A. R., Halberg, R. B., and Dove, W. F. (2004). Tumor regionality in the mouse intestine reflects the mechanism of loss of Apc function. Proc Natl Acad Sci U S A 101, 9769-9773.

Hajishengallis, G., and Lambris, J. D. (2010). Crosstalk pathways between Toll-like receptors and the complement system. Trends Immunol 31, 154-163. 
Hollmann, T. J., Mueller-Ortiz, S. L., Braun, M. C., and Wetsel, R. A. (2008). Disruption of the C5a receptor gene increases resistance to acute Gram-negative bacteremia and endotoxic shock: opposing roles of C3a and C5a. Mol Immunol 45, 1907-1915.

Huang, W. Y., Hsu, S. D., Huang, H. Y., Sun, Y. M., Chou, C. H., Weng, S. L., and Huang, H. D. (2015). MethHC: a database of DNA methylation and gene expression in human cancer. Nucleic Acids Res 43, D856-861.

Huycke, M. M., Abrams, V., and Moore, D. R. (2002). Enterococcus faecalis produces extracellular superoxide and hydrogen peroxide that damages colonic epithelial cell DNA. Carcinogenesis 23, 529-536.

Huycke, M. M., and Moore, D. R. (2002). In vivo production of hydroxyl radical by Enterococcus faecalis colonizing the intestinal tract using aromatic hydroxylation. Free Radic Biol Med 33, 818-826.

Irizarry, R. A., Ladd-Acosta, C., Wen, B., Wu, Z., Montano, C., Onyango, P., Cui, H., Gabo, K., Rongione, M., Webster, M., et al. (2009). The human colon cancer methylome shows similar hypo- and hypermethylation at conserved tissue-specific $\mathrm{CpG}$ island shores. Nat Genet 41, 178186.

Janakiram, N. B., and Rao, C. V. (2014). The role of inflammation in colon cancer. Adv Exp Med Biol 816, 25-52.

Jung, G., Hernandez-Illan, E., Moreira, L., Balaguer, F., and Goel, A. (2020). Epigenetics of colorectal cancer: biomarker and therapeutic potential. Nat Rev Gastroenterol Hepatol 17, 111130. 
Kildsgaard, J., Hollmann, T. J., Matthews, K. W., Bian, K., Murad, F., and Wetsel, R. A. (2000). Cutting edge: targeted disruption of the $\mathrm{C} 3$ a receptor gene demonstrates a novel protective antiinflammatory role for C3a in endotoxin-shock. J Immunol 165, 5406-5409.

Kumar, P., Monin, L., Castillo, P., Elsegeiny, W., Horne, W., Eddens, T., Vikram, A., Good, M., Schoenborn, A. A., Bibby, K., et al. (2016). Intestinal Interleukin-17 Receptor Signaling Mediates Reciprocal Control of the Gut Microbiota and Autoimmune Inflammation. Immunity 44, 659-671.

Langmead, B., and Salzberg, S. L. (2012). Fast gapped-read alignment with Bowtie 2. Nat Methods 9, 357-359.

Lee, J. S., Tato, C. M., Joyce-Shaikh, B., Gulen, M. F., Cayatte, C., Chen, Y., Blumenschein, W. M., Judo, M., Ayanoglu, G., McClanahan, T. K., et al. (2015). Interleukin-23-Independent IL-17 Production Regulates Intestinal Epithelial Permeability. Immunity 43, 727-738.

Lefrancois, L., and Lycke, N. (2001). Isolation of mouse small intestinal intraepithelial lymphocytes, Peyer's patch, and lamina propria cells. Curr Protoc Immunol Chapter 3, Unit 319. Liao, Y., Smyth, G. K., and Shi, W. (2014). featureCounts: an efficient general purpose program for assigning sequence reads to genomic features. Bioinformatics 30, 923-930.

Magoc, T., and Salzberg, S. L. (2011). FLASH: fast length adjustment of short reads to improve genome assemblies. Bioinformatics 27, 2957-2963.

Manzari, C., Chiara, M., Costanza, A., Leoni, C., Volpicella, M., Picardi, E., D'Erchia, A. M., Placido, A., Trotta, M., Horner, D. S., et al. (2014). Draft genome sequence of Sphingobium sp. strain ba1, resistant to kanamycin and nickel ions. FEMS Microbiol Lett 361, 8-9. 
Mariathasan, S., Turley, S. J., Nickles, D., Castiglioni, A., Yuen, K., Wang, Y., Kadel, E. E., III, Koeppen, H., Astarita, J. L., Cubas, R., et al. (2018). TGFbeta attenuates tumour response to PDL1 blockade by contributing to exclusion of T cells. Nature 554, 544-548.

Maru, G. B., Gandhi, K., Ramchandani, A., and Kumar, G. (2014). The role of inflammation in skin cancer. Adv Exp Med Biol 816, 437-469.

McCarthy, D. J., Chen, Y., and Smyth, G. K. (2012). Differential expression analysis of multifactor RNA-Seq experiments with respect to biological variation. Nucleic Acids Res 40, $4288-4297$.

McMurdie, P. J., and Holmes, S. (2013). phyloseq: an R package for reproducible interactive analysis and graphics of microbiome census data. PLoS One 8, e61217.

Moser, A. R., Pitot, H. C., and Dove, W. F. (1990). A dominant mutation that predisposes to multiple intestinal neoplasia in the mouse. Science 247, 322-324.

Munkholm, P. (2003). Review article: the incidence and prevalence of colorectal cancer in inflammatory bowel disease. Aliment Pharmacol Ther 18 Suppl 2, 1-5.

Neufert, C., Becker, C., and Neurath, M. F. (2007). An inducible mouse model of colon carcinogenesis for the analysis of sporadic and inflammation-driven tumor progression. Nat Protoc 2, 1998-2004.

Ning, C., Li, Y. Y., Wang, Y., Han, G. C., Wang, R. X., Xiao, H., Li, X. Y., Hou, C. M., Ma, Y. F., Sheng, D. S., et al. (2015). Complement activation promotes colitis-associated carcinogenesis through activating intestinal IL-1beta/IL-17A axis. Mucosal Immunol 8, 1275-1284.

Nordahl, E. A., Rydengard, V., Nyberg, P., Nitsche, D. P., Morgelin, M., Malmsten, M., Bjorck, L., and Schmidtchen, A. (2004). Activation of the complement system generates antibacterial peptides. Proc Natl Acad Sci U S A 101, 16879-16884. 
Olcina, M. M., Balanis, N. G., Kim, R. K., Aksoy, B. A., Kodysh, J., Thompson, M. J., Hammerbacher, J., Graeber, T. G., and Giaccia, A. J. (2018). Mutations in an Innate Immunity Pathway Are Associated with Poor Overall Survival Outcomes and Hypoxic Signaling in Cancer. Cell Rep 25, 3721-3732 e3726.

Omenetti, S., Bussi, C., Metidji, A., Iseppon, A., Lee, S., Tolaini, M., Li, Y., Kelly, G., Chakravarty, P., Shoaie, S., et al. (2019). The Intestine Harbors Functionally Distinct Homeostatic Tissue-Resident and Inflammatory Th17 Cells. Immunity 51, 77-89 e76.

Ostvik, A. E., Granlund, A., Gustafsson, B. I., Torp, S. H., Espevik, T., Mollnes, T. E., Damas, J. K., and Sandvik, A. K. (2014). Mucosal toll-like receptor 3-dependent synthesis of complement factor B and systemic complement activation in inflammatory bowel disease. Inflamm Bowel Dis 20, 995-1003.

Page, A. J., Cummins, C. A., Hunt, M., Wong, V. K., Reuter, S., Holden, M. T., Fookes, M., Falush, D., Keane, J. A., and Parkhill, J. (2015). Roary: rapid large-scale prokaryote pan genome analysis. Bioinformatics 31, 3691-3693.

Pancione, M., Remo, A., and Colantuoni, V. (2012). Genetic and epigenetic events generate multiple pathways in colorectal cancer progression. Patholog Res Int 2012, 509348.

Polakis, P. (2012). Wnt signaling in cancer. Cold Spring Harb Perspect Biol 4.

Rakoff-Nahoum, S., and Medzhitov, R. (2007). Regulation of spontaneous intestinal tumorigenesis through the adaptor protein MyD88. Science 317, 124-127.

Salcedo, R., Worschech, A., Cardone, M., Jones, Y., Gyulai, Z., Dai, R. M., Wang, E., Ma, W., Haines, D., O'HUigin, C., et al. (2010). MyD88-mediated signaling prevents development of adenocarcinomas of the colon: role of interleukin 18. J Exp Med 207, 1625-1636. 
Salzman, N. H., Hung, K., Haribhai, D., Chu, H., Karlsson-Sjoberg, J., Amir, E., Teggatz, P., Barman, M., Hayward, M., Eastwood, D., et al. (2010). Enteric defensins are essential regulators of intestinal microbial ecology. Nat Immunol 11, 76-83.

Sears, C. L., and Garrett, W. S. (2014). Microbes, microbiota, and colon cancer. Cell Host Microbe 15, 317-328.

Segata, N., Bornigen, D., Morgan, X. C., and Huttenhower, C. (2013). PhyloPhlAn is a new method for improved phylogenetic and taxonomic placement of microbes. Nat Commun 4, 2304. Senol, K., Ozkan, M. B., Vural, S., and Tez, M. (2014). The role of inflammation in gastric cancer. Adv Exp Med Biol 816, 235-257.

Siegel, R. L., Jakubowski, C. D., Fedewa, S. A., Davis, A., and Azad, N. S. (2020). Colorectal Cancer in the Young: Epidemiology, Prevention, Management. Am Soc Clin Oncol Educ Book $40,1-14$

Siegel, R. L., Miller, K. D., and Jemal, A. (2018). Cancer statistics, 2018. CA Cancer J Clin 68, 7-30.

Sobhani, I., Tap, J., Roudot-Thoraval, F., Roperch, J. P., Letulle, S., Langella, P., Corthier, G., Tran Van Nhieu, J., and Furet, J. P. (2011). Microbial dysbiosis in colorectal cancer (CRC) patients. PLoS One 6, e16393.

Tilg, H., Adolph, T. E., Gerner, R. R., and Moschen, A. R. (2018). The Intestinal Microbiota in Colorectal Cancer. Cancer Cell 33, 954-964.

Tse, J. W. T., Jenkins, L. J., Chionh, F., and Mariadason, J. M. (2017). Aberrant DNA Methylation in Colorectal Cancer: What Should We Target? Trends Cancer 3, 698-712. 
Vaishnava, S., Yamamoto, M., Severson, K. M., Ruhn, K. A., Yu, X., Koren, O., Ley, R., Wakeland, E. K., and Hooper, L. V. (2011). The antibacterial lectin RegIIIgamma promotes the spatial segregation of microbiota and host in the intestine. Science 334, 255-258.

Wang, K., Kim, M. K., Di Caro, G., Wong, J., Shalapour, S., Wan, J., Zhang, W., Zhong, Z., Sanchez-Lopez, E., Wu, L. W., et al. (2014). Interleukin-17 receptor a signaling in transformed enterocytes promotes early colorectal tumorigenesis. Immunity 41, 1052-1063.

Wang, T., Cai, G., Qiu, Y., Fei, N., Zhang, M., Pang, X., Jia, W., Cai, S., and Zhao, L. (2012). Structural segregation of gut microbiota between colorectal cancer patients and healthy volunteers. ISME J 6, 320-329.

Wang, X., Yang, Y., and Huycke, M. M. (2015). Commensal bacteria drive endogenous transformation and tumour stem cell marker expression through a bystander effect. Gut 64,459 468.

Watanabe, N., Kaminuma, O., Kitamura, N., and Hiroi, T. (2016). Induced Treg Cells Augment the Th17-Mediated Intestinal Inflammatory Response in a CTLA4-Dependent Manner. PLoS One 11, e0150244.

Wu, M. C., Brennan, F. H., Lynch, J. P., Mantovani, S., Phipps, S., Wetsel, R. A., Ruitenberg, M. J., Taylor, S. M., and Woodruff, T. M. (2013). The receptor for complement component C3a mediates protection from intestinal ischemia-reperfusion injuries by inhibiting neutrophil mobilization. Proc Natl Acad Sci U S A 110, 9439-9444.

Wu, S., Rhee, K. J., Albesiano, E., Rabizadeh, S., Wu, X., Yen, H. R., Huso, D. L., Brancati, F. L., Wick, E., McAllister, F., et al. (2009). A human colonic commensal promotes colon tumorigenesis via activation of T helper type $17 \mathrm{~T}$ cell responses. Nat Med 15, 1016-1022. 
Xiao, Q., Wu, J., Wang, W. J., Chen, S., Zheng, Y., Yu, X., Meeth, K., Sahraei, M., Bothwell, A. L. M., Chen, L., et al. (2018). DKK2 imparts tumor immunity evasion through beta-cateninindependent suppression of cytotoxic immune-cell activation. Nat Med 24, 262-270.

Zhang, X., Kimura, Y., Fang, C., Zhou, L., Sfyroera, G., Lambris, J. D., Wetsel, R. A., Miwa, T., and Song, W. C. (2007). Regulation of Toll-like receptor-mediated inflammatory response by complement in vivo. Blood 110, 228-236. 


\section{Figure 1}
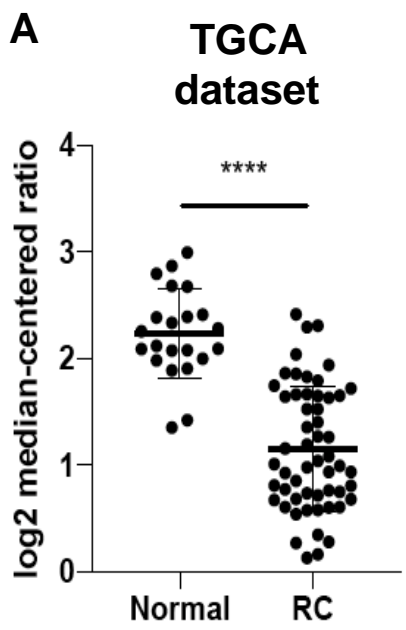

B

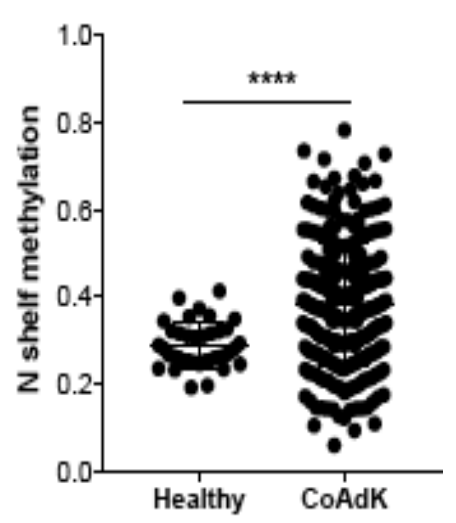

Skrzypczak dataset

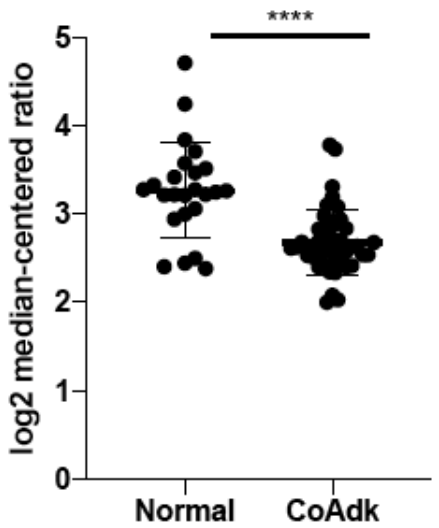

C

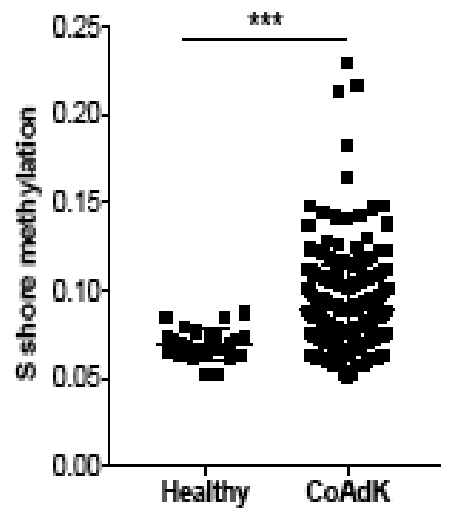

Sabates-Bellver dataset
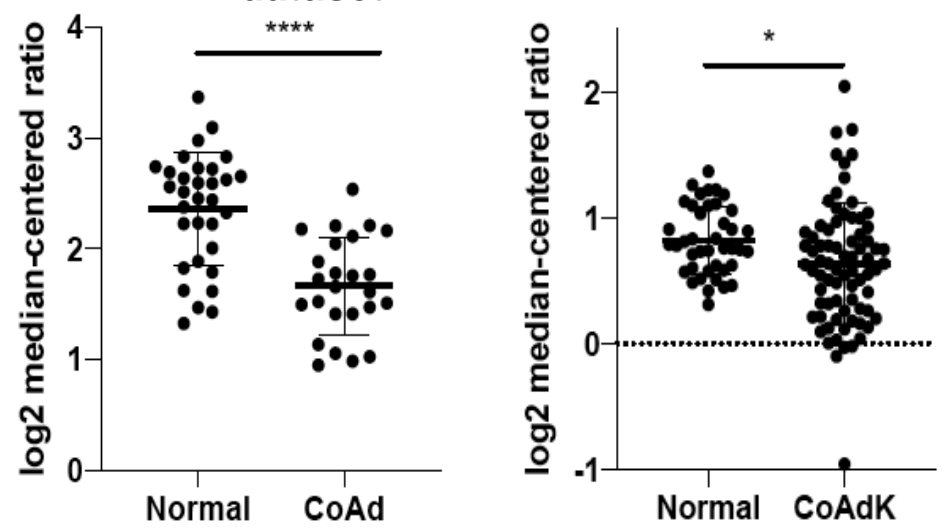

Ki colon dataset

ormal CoAdK

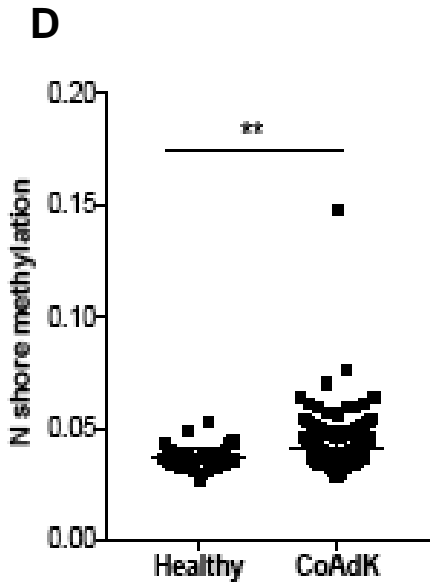




\section{Figure 2}

A

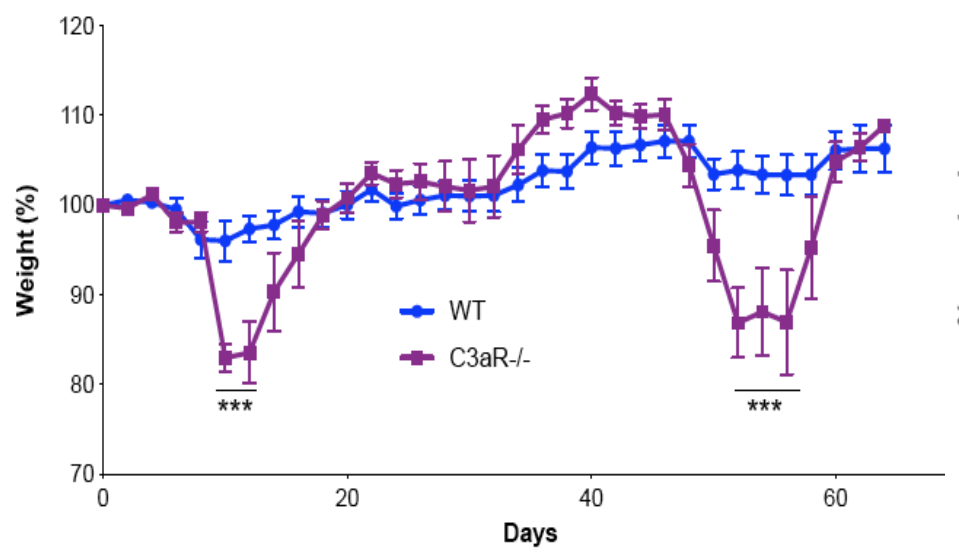

C

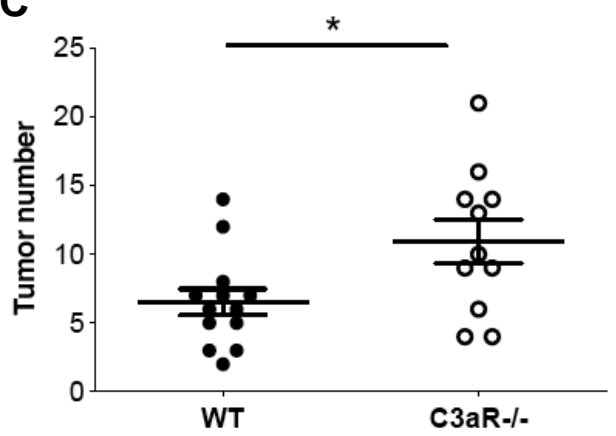

F

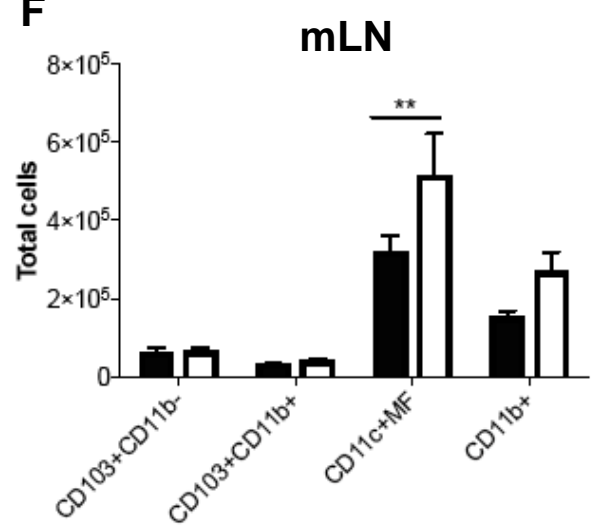

D

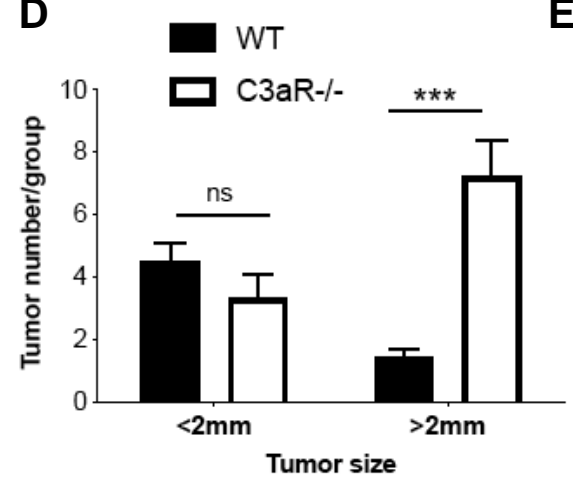

E
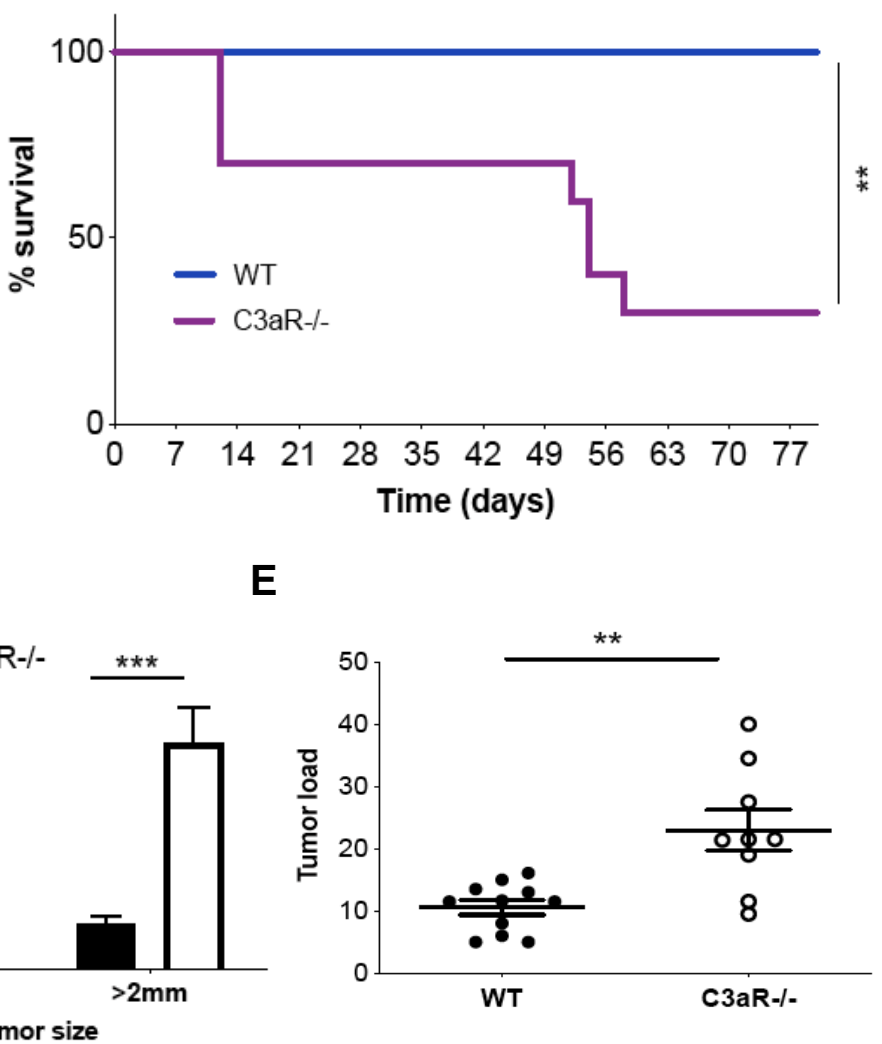

$\mathbf{G}_{8 \times 10^{5}} \quad \mathbf{m L N} \quad \mathbf{H}$

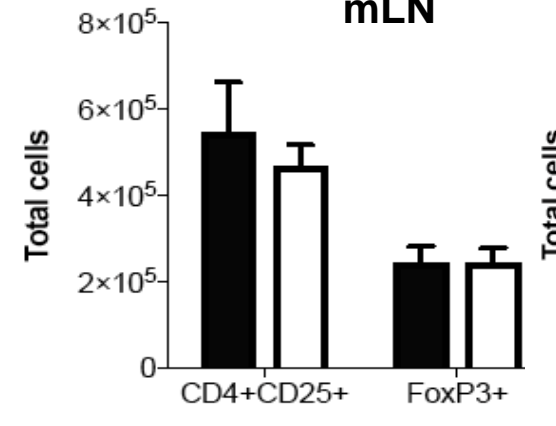

H
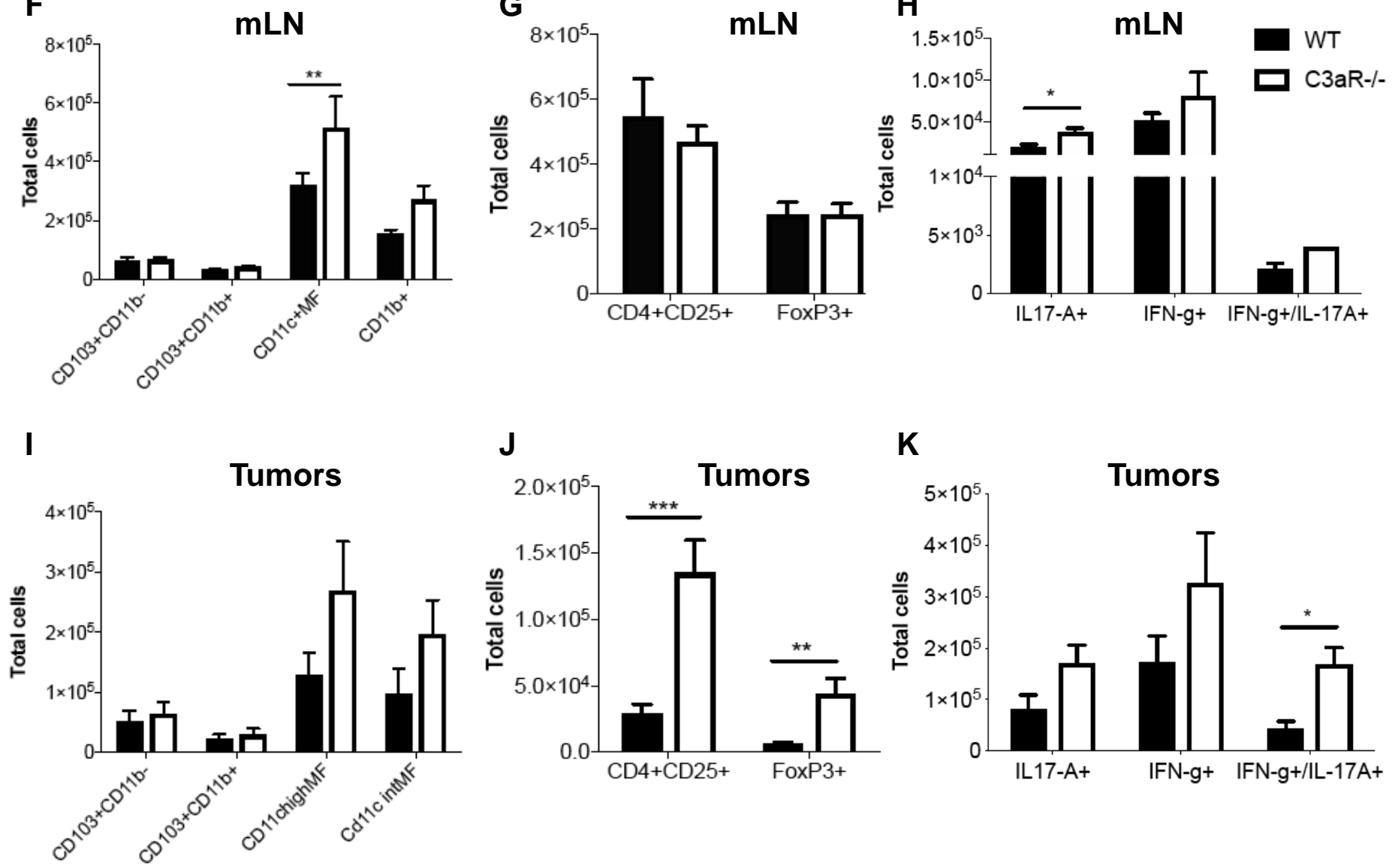

K

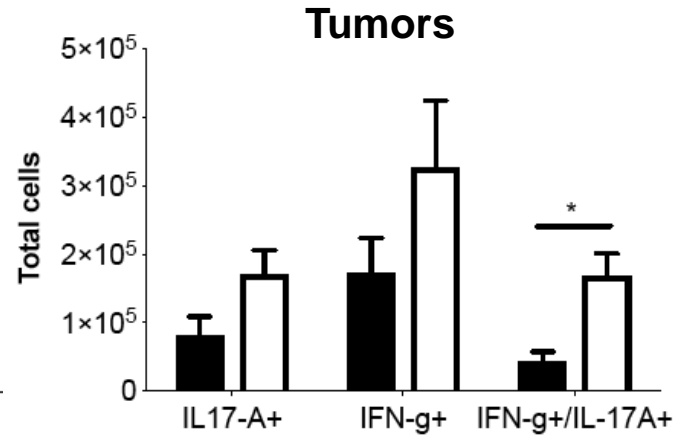




\section{Figure 3}

A

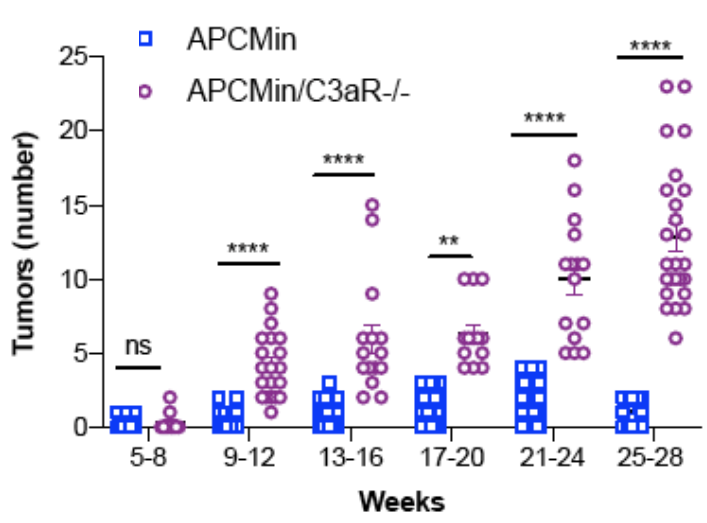

B

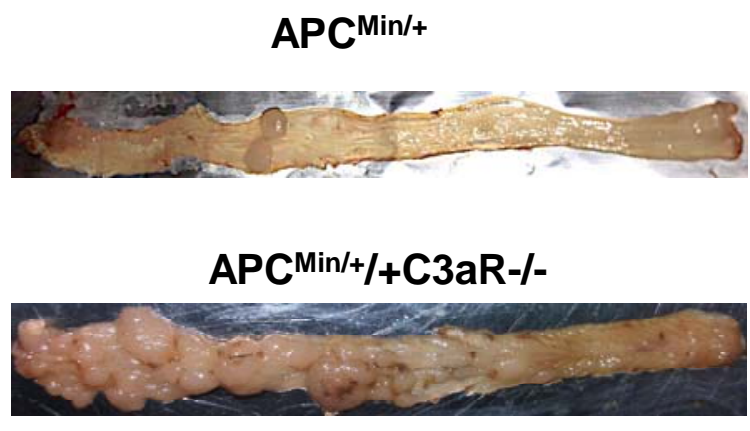

E

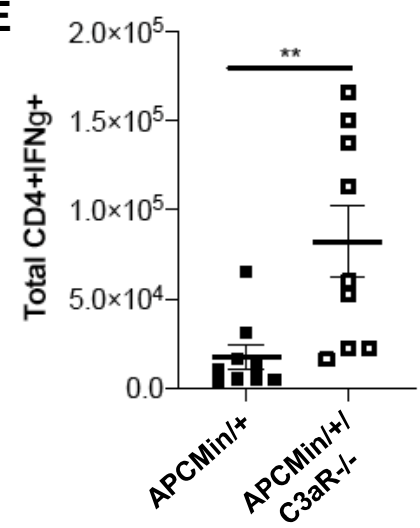

H

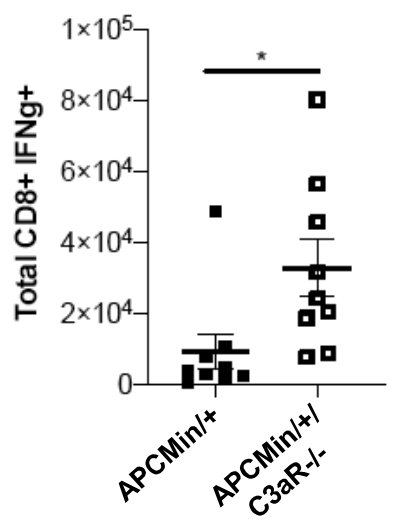


bioRxiv preprint doi: https://doi.org/10.1101/2021.01.18.426963; this version posted January 19, 2021. The copyright holder for this preprint (which was not certified by peer review) is the author/funder. All rights reserved. No reuse allowed without permission.

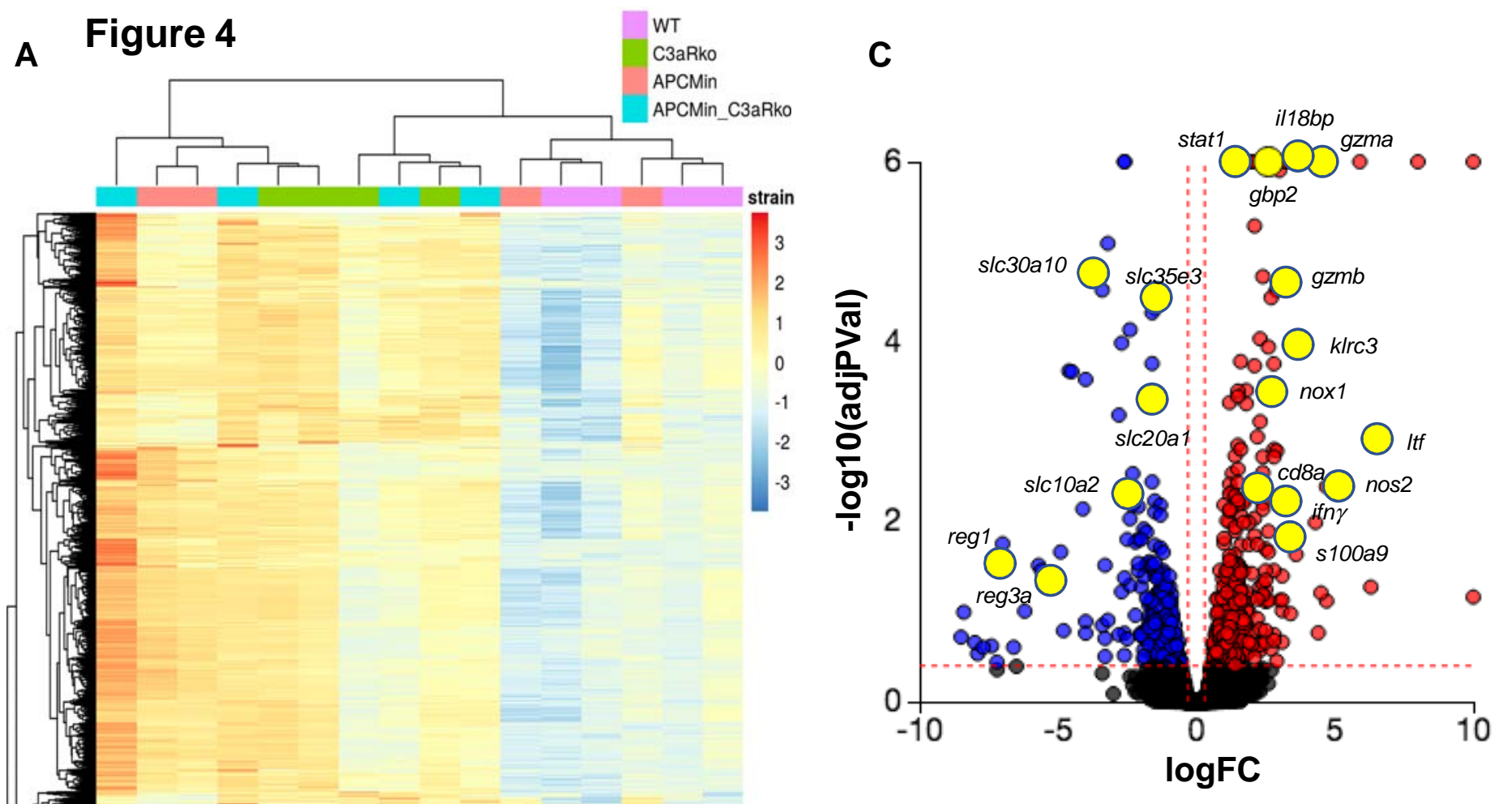

B

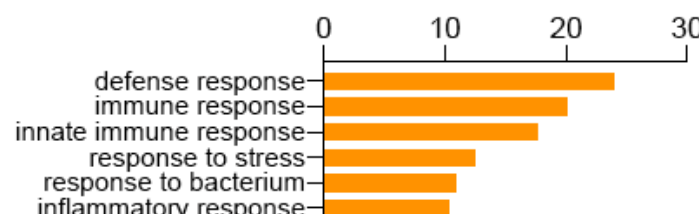

positive regulation of inflammatory response

response to molecule of bacterial originresponse to interferon-gamma cytokine production

interferon-gamma adaptive immune response response to cytokine-

humoral immune response

cytokine-mediated signaling pathway-

type I interferon signaling pathway-

regulation of inflammatory response-

cell proliferation

lymphocyte mediated immunity

regulation of $T$ cell activation

leukocyte cell-cell adhesion-

cytokine secretion

regulation of lymphocyte activation reactive oxygen species metabolic process- 
bioRxiv preprint doi: https://doi.org/10.1101/2021.01.18.426963; this version posted January 19, 2021. The copyright holder for this preprint (which was not certified by peer review) is the author/funder. All rights reserved. No reuse allowed without permission.

Figure 5

A
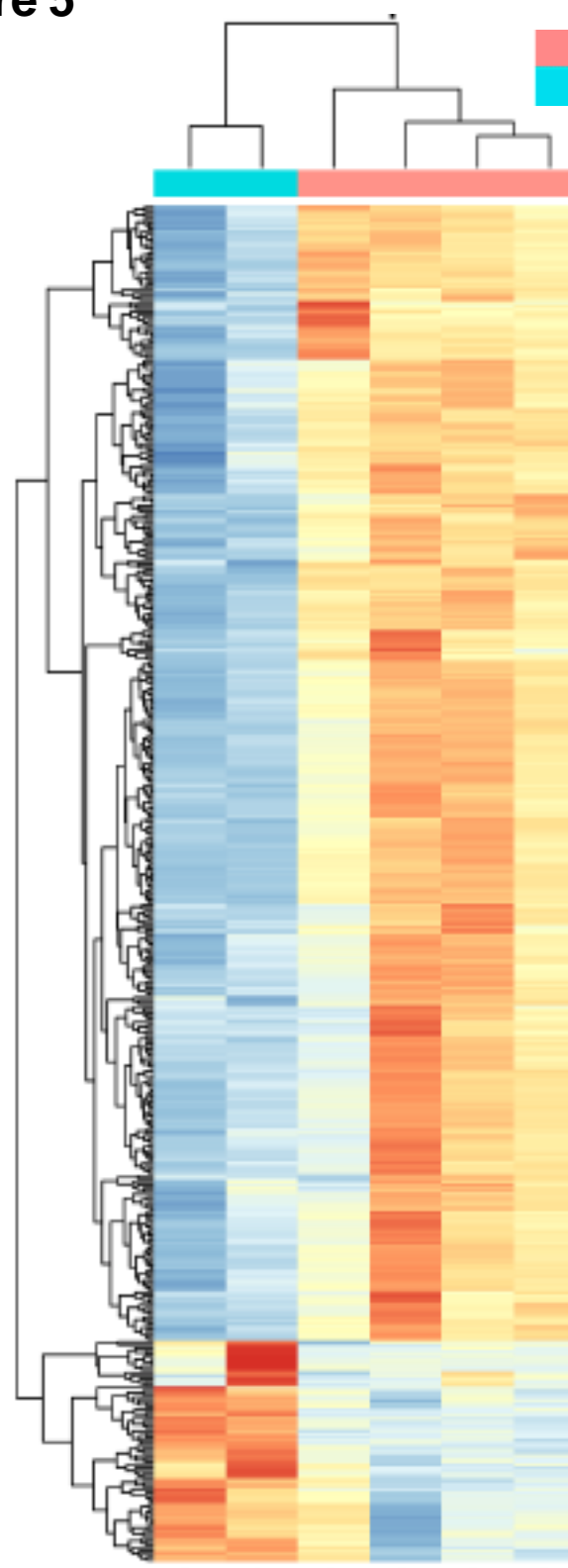

$\mathrm{APC}^{\mathrm{Min} /+} / \mathrm{C} 3 \mathrm{aR}-/-$ APC $^{\mathrm{Min} /+}$
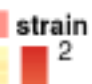

0

$-1$

$-2$
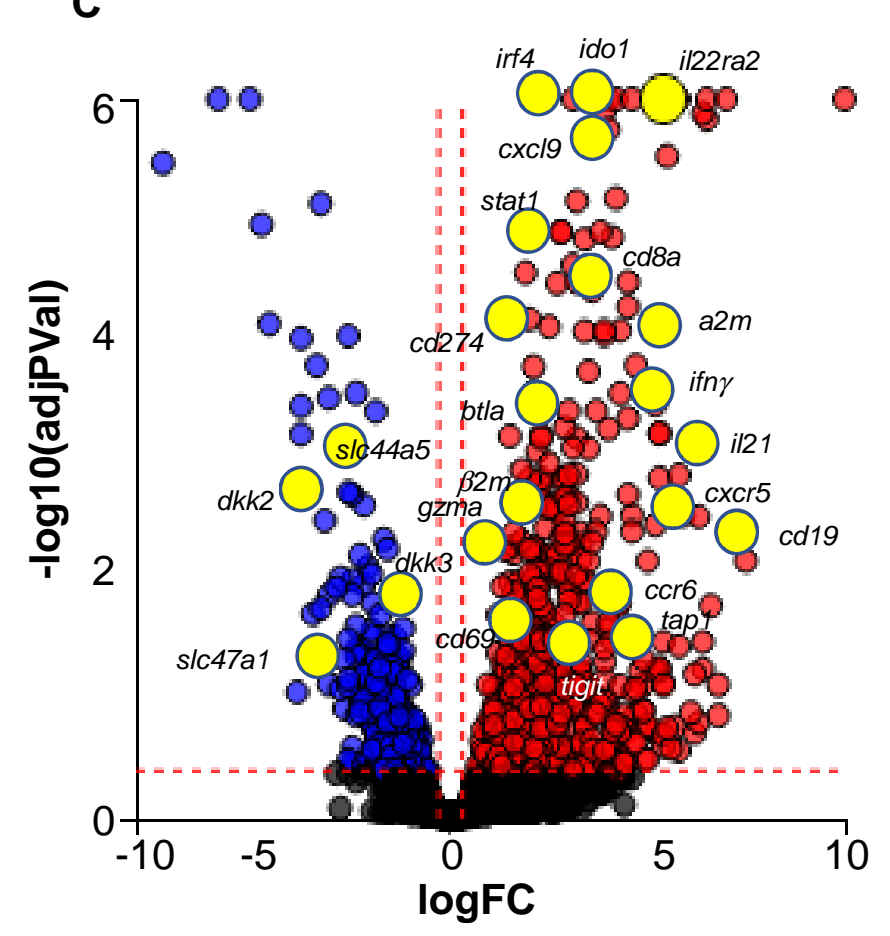

C

B

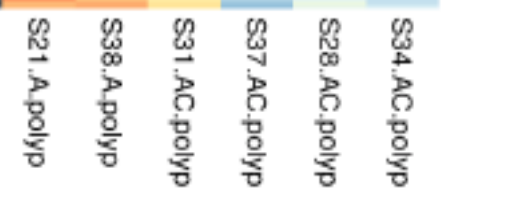




\section{Figure 6}

A

DONORS<smiles>CCCCC</smiles>

APCMin/C3aR-/-

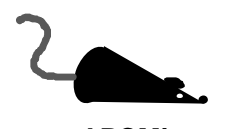

APCMin

Abx
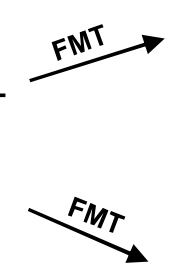

FMT (gavage)
RECIPIENTS

(Abx treated)
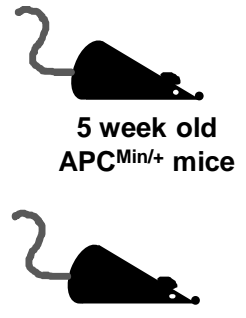

5 week old APC $^{\mathrm{Min} /+}$ mice
B

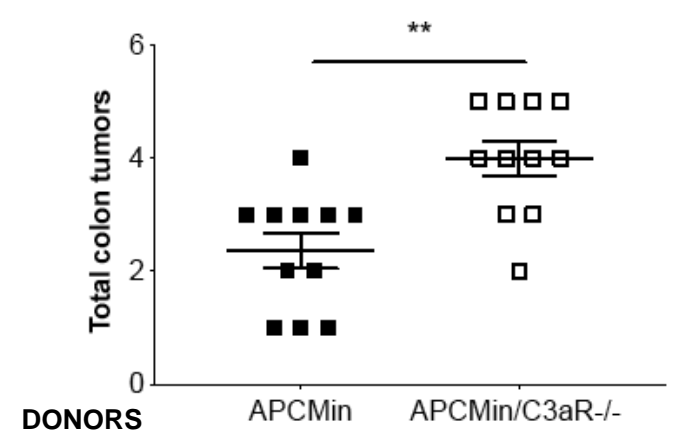

C

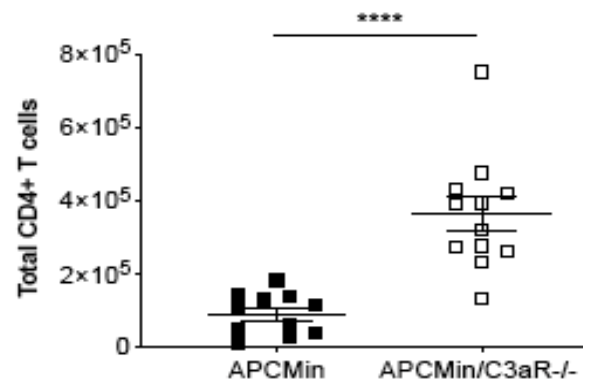

F

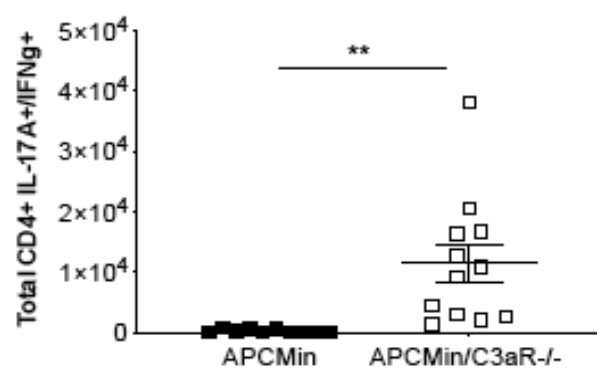

D

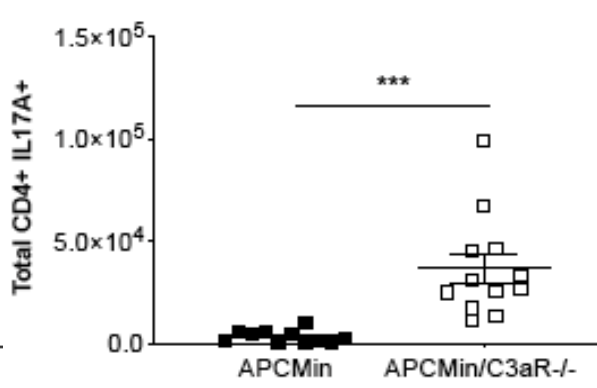

G

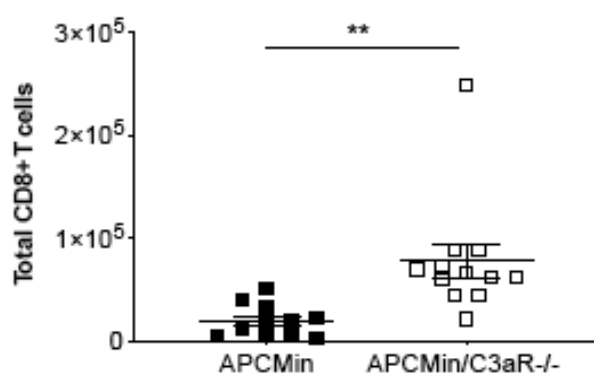

E

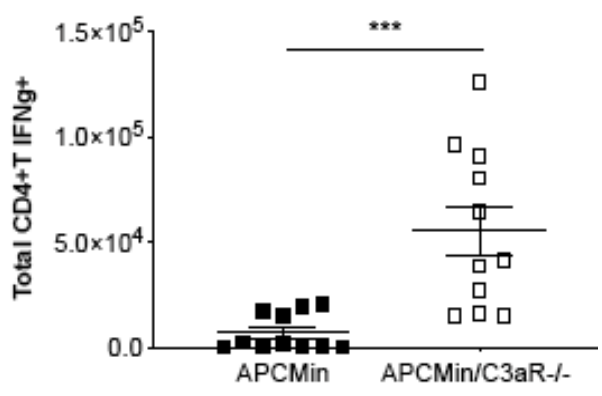

H

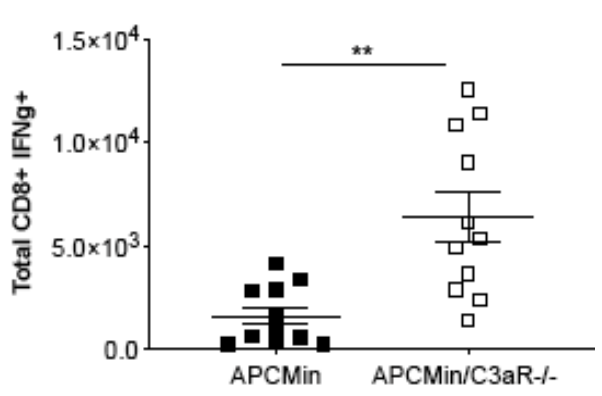




\section{Figure 7}

A

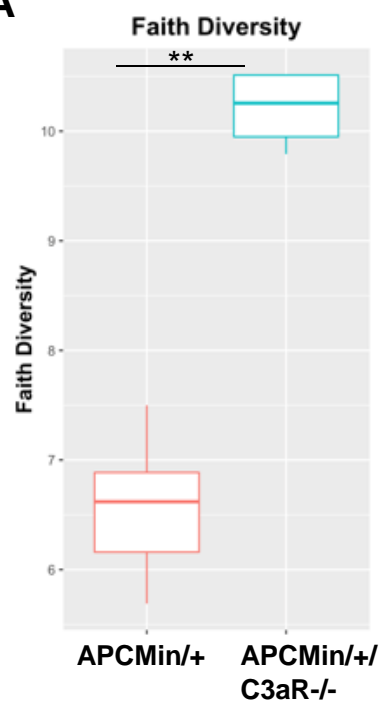

B
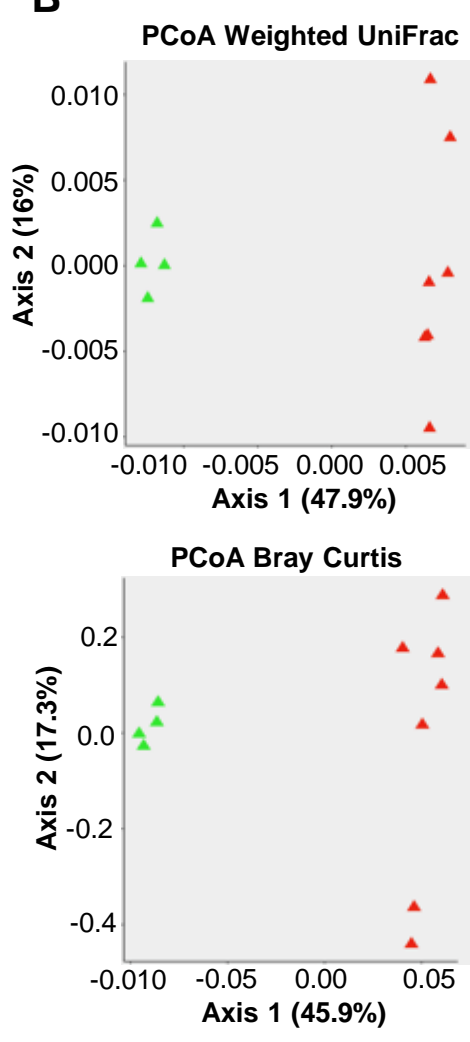

\section{C}

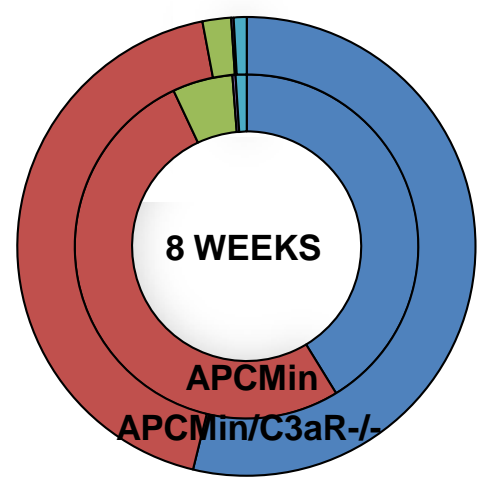

8 WEEKS
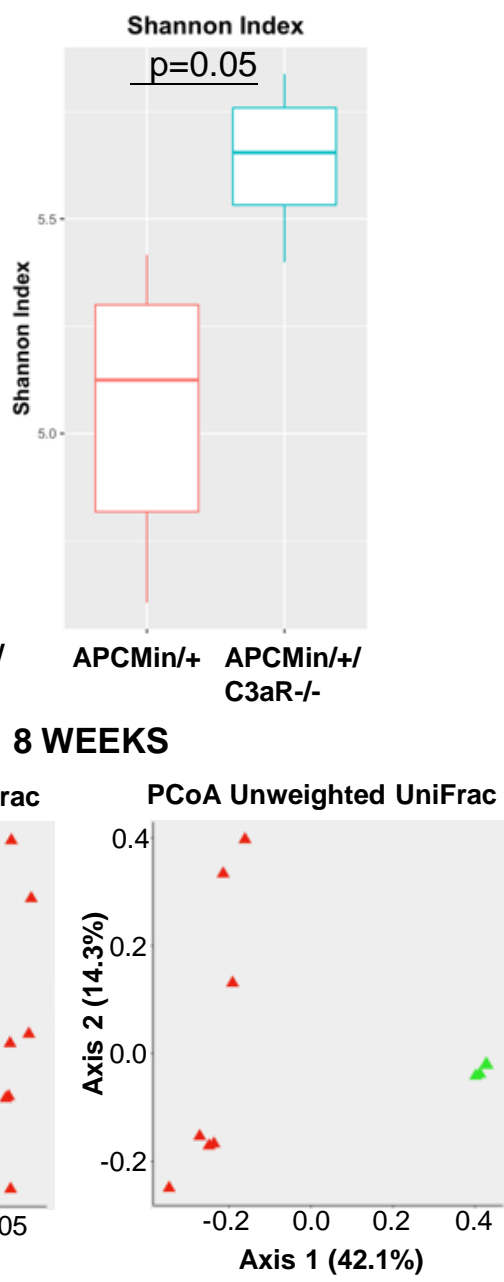

QFirmicutes

口Bscteroldetes

口Prolucbacleria

- Tenericutes

口 Less abundent phyli
12 WEEKS

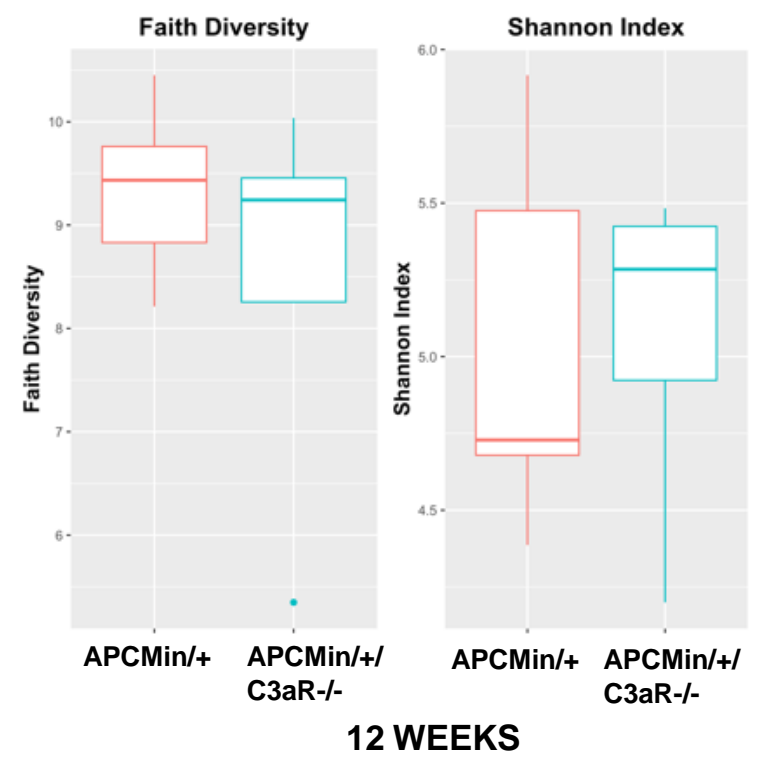

PCoA Weighted UniFrac

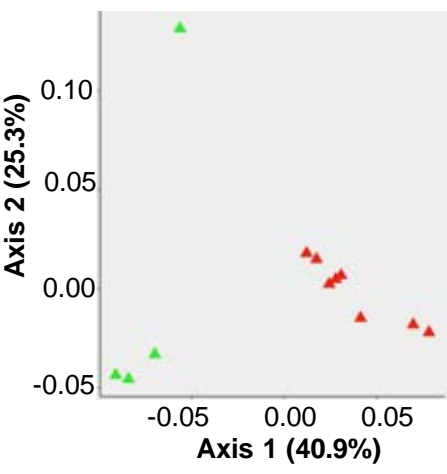

PCoA Unweighted UniFrac
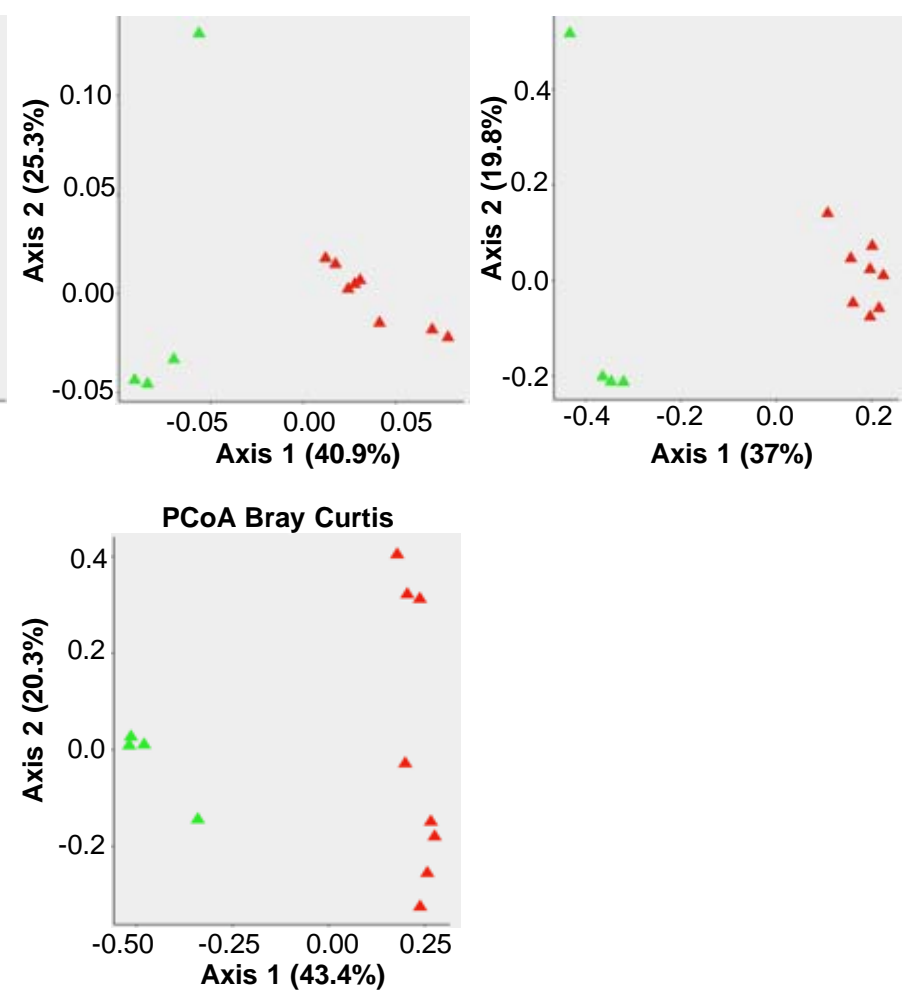
Figure 8

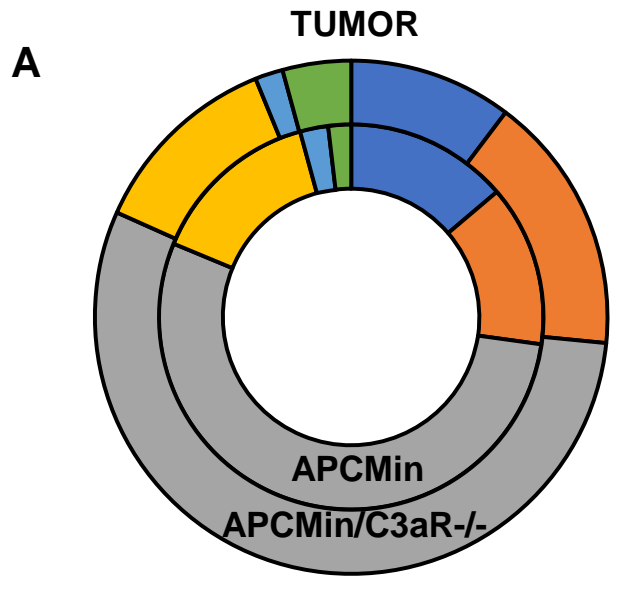

口Actinobacteria

口Bacteroidetes

口Firmicutes

口Proteobacteria

口Verrucomicrobia

口Less abundant phyla

B

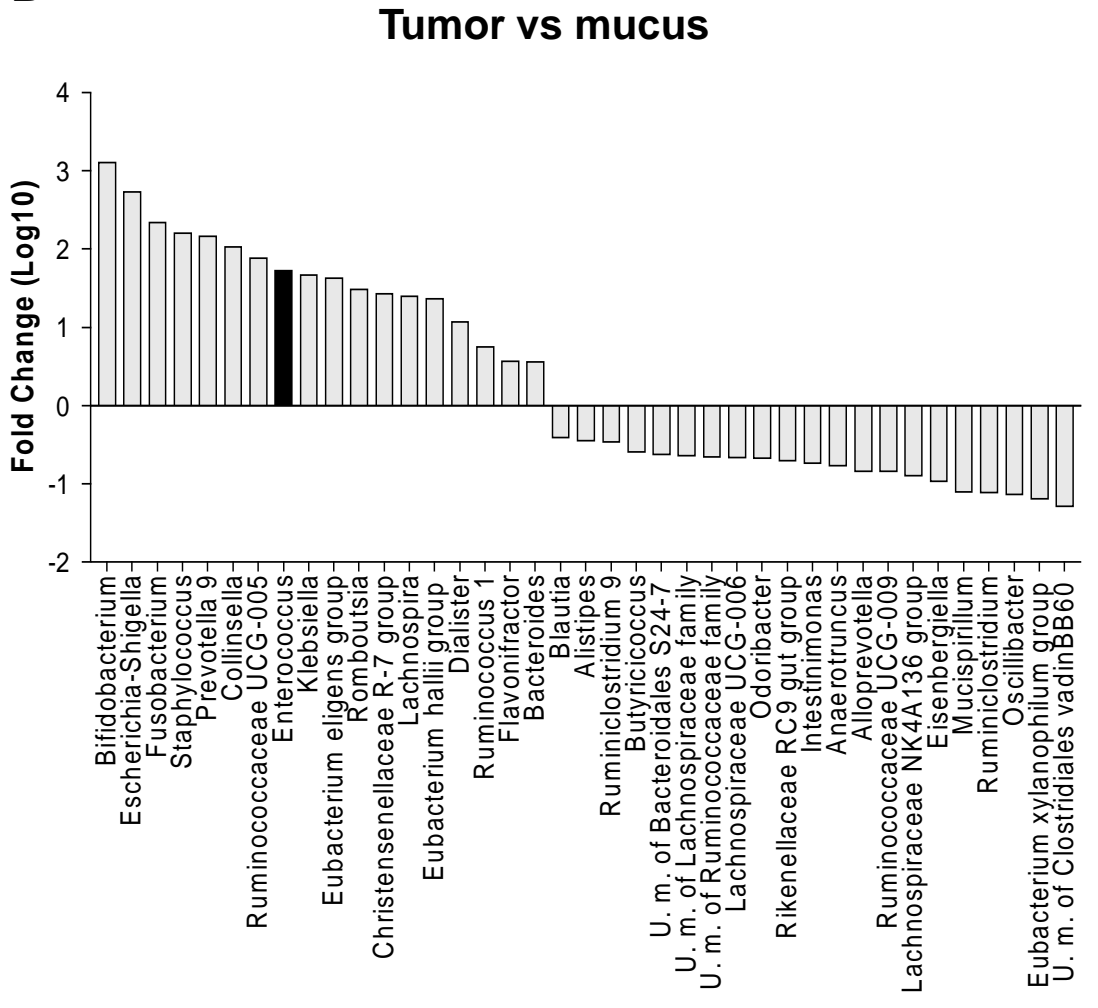

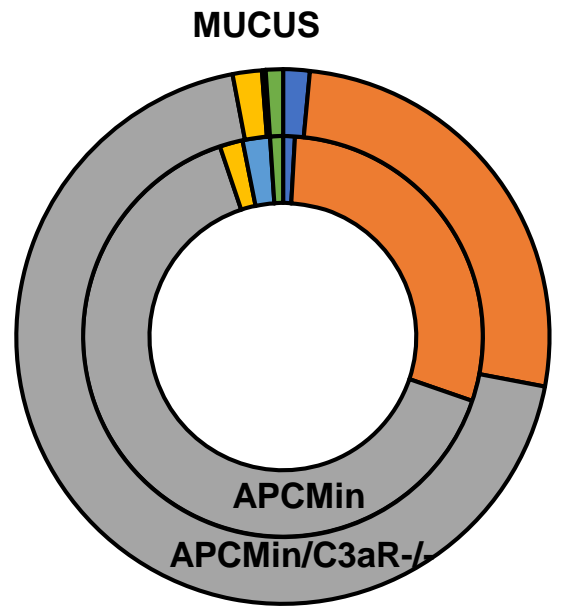

C

\section{$\mathrm{APC}^{\mathrm{Min} /+} / \mathrm{C} 3 \mathrm{aR}-/-$ tumors: $12 \mathrm{wks}$ vs 16 wks}

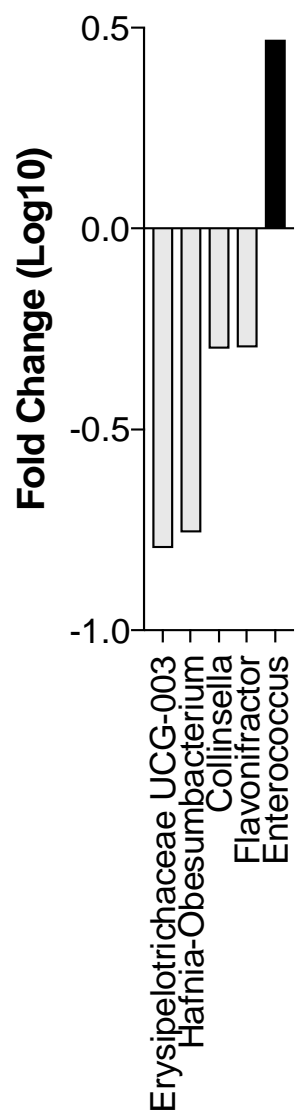




\section{Figure 9}

A

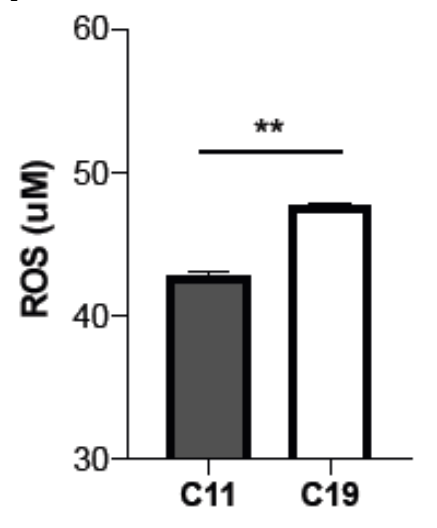

B

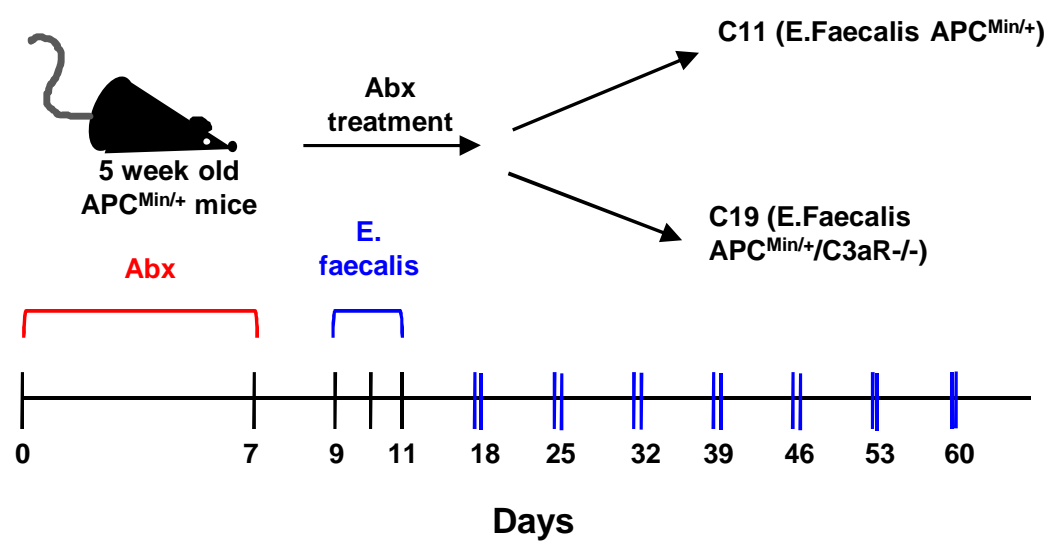

D

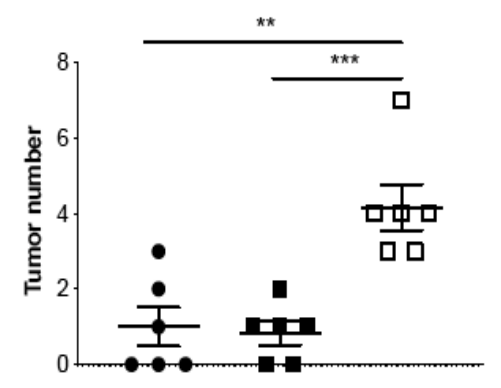

E

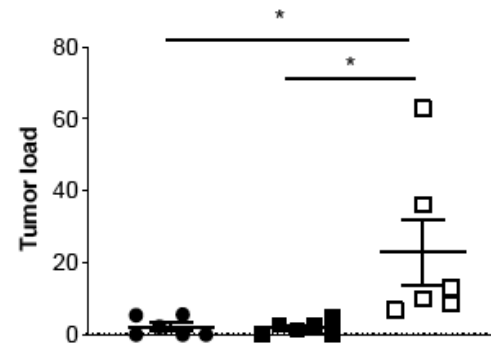

F

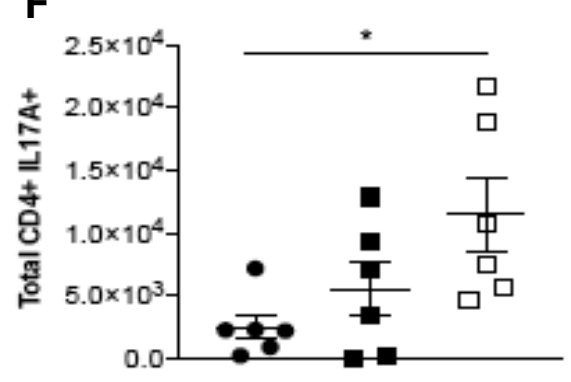

G

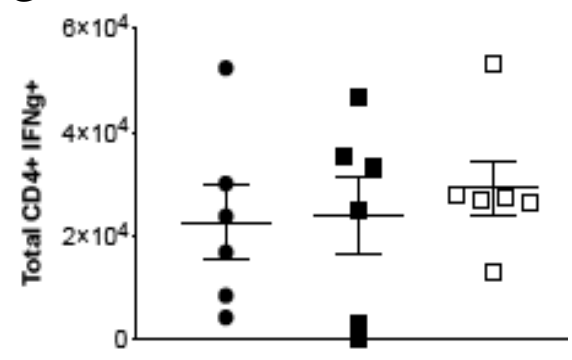

I
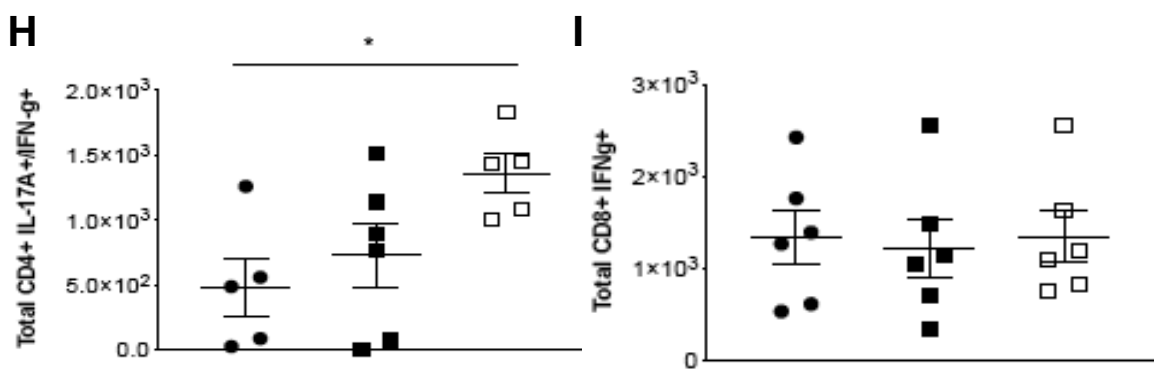

Ctrl

C11

C19 